\title{
VICTIMIZACIÓN PENITENCIARIA
}

\author{
David Lorenzo Morillas Fernández \\ Profesor Titular de Derecho Penal y Criminología \\ Universidad de Murcia \\ Email: davidm@um.es
}

RESUMEN: El presente artículo trata de realizar una aproximación al ámbito de la victimización penitenciaria, temática prácticamente inexplorada por los investigadores. Para ello, se parte de la Victimología, como disciplina científica poseedora de las herramientas necesarias para delimitar la fenomenología y características de la victimización penitenciaria; se continúa por un breve análisis de los perfiles de la población reclusa española; para finalizar uniendo las variables anteriores en el contexto de la victimización penitenciaria, procediendo a su delimitación conceptual y análisis de sus principales tipologías, focalizadas al ámbito institucional y de victimización propiamente dicho.

PALABRAS CLAVE: Victimización penitenciaria, Victimología, prisión, victimización institucional.

ABSTRACT: The present article tries to approach the scope of penitentiary victimization, a topic almost unexplored by researchers. First of all, it is part of the Victimology, as a scientific discipline possessing the necessary tools to delimit the phenomenology and characteristics of penitentiary victimization; secondly, it includes a brief analysis of the profiles of the Spanish prison population; and third, there is an analysis of the previous variables in the context of penitentiary victimization, proceeding to its conceptual delimitation and analysis of its main typologies, focused on the institutional scope and the victimization itself.

KEY WORDS: Penitentiary victimization, Victimology, prison, institutional victimization.

SUMARIO: I. DELIMITACIÓN CONCEPTUAL. 1. La Victimología como punto de partida. 2. Tipos de victimización. 3. Breve referencia a datos estadísticos penitenciarios. 3.1. Tamaño de la población reclusa. 3.2. Género. 3.3. Edad. 3.4. Nacionalidad. 3.5.Tipología delictiva. 3.6. Grado de tratamiento. II. VICTIMIZACIÓN PENITENCIARIA. III. CONCLUSIONES.

\section{DELIMITACIÓN CONCEPTUAL}




\section{La Victimología como punto de partida.}

El fenómeno de la victimización penitenciaria constituye un ámbito de estudio al que no se le ha prestado la debida atención a lo largo de la historia por diversos motivos: tardía aparición de la Victimología, escasez de información institucional, temor, en determinadas ocasiones, a mostrar la realidad penitenciaria tal y como era, ausencia de atención y garantías a los procesos desarrollados en el interior de los centros penitenciarios, sobre los cuales la sociedad ha vivido durante bastantes años de espaldas a la realidad social y humana que convive diariamente dentro de los muros delimitadores de las prisiones, a veces, según el momento histórico correspondiente, por ser considerados como lugares de castigo y aislamiento respecto de los cuales la propia arquitectura de la prisión servía de aislamiento de cara al exterior, sin importar los dramas y problemas sociales existentes en su interior, situación que, afortunadamente en los países avanzados ha cambiado en favor de la consideración de las prisiones como centros abiertos o instituciones globales sobre los que subyacen todo un sistema de garantías personales e institucionales sometidos a la potestad jurisdiccional.

En esencia, la victimización penitenciaria no es más que un proceso normal de victimización, idéntico al producido dentro de la sociedad en sí, con la única particularidad de que queda reducido al ámbito de los centros penitenciarios, lo cual puede conllevar algunas dificultades adicionales en cuanto a su detección, dadas las variables confluentes entre el colectivo de sujetos activos que desarrollarían los ilícitos vinculados y la hipotética presencia una victimización institucional, carente de un rostro físico al que imputar la conducta ilícita.

Conforme a lo anterior, como fenómeno habitual y lógico dentro del correcto devenir de la sociedad, la citada victimización es el resultado de la confluencia de tres campos de conocimiento: el Derecho Penal, la Criminología y la Victimología, con la especial particularidad, ya referida, de que su ámbito de actuación queda reducido a la esfera penitenciaria, por lo que habría que sumar un cuarto elemento regulador de las específicas relaciones entre los sujetos intervinientes, lo cual denotará, como referiré expresamente en el epígrafe siguiente, un auténtico marco meramente situacional pero con indudables connotaciones sociales, políticas y criminógenas. 
Dejando de lado, momentáneamente, esta cuarta variable, la confluencia de las tres primeras no constituye, reitero, un hecho extraordinaria sino común al igual que acontece en el marco de la propia sociedad en tanto la clásica trisomía delincuente, delito y víctima vuelve a encontrar aquí un nuevo punto de inflexión con la consabida confluencia de los campos de conocimiento anteriormente citados.

Responder a la secuenciación de las variables citadas no resulta una cuestión baladí. En principio, los elementos lógicos vendrían configurados por la presencia de un delincuente, que ejecutará un hecho ilícito (delito o conducta antisocial) respecto de una víctima -individual o grupal-. Sin embargo, para poder calificar como tal al sujeto que realiza la acción criminal primero debe existir la consideración "delito", sin la cual no podrá preestablecerse ni delimitar la figura del delincuente. No obstante, en lo que ahora interesa, conviene centrar la atención en la perspectiva victimológica, la cual permitirá comprender las razones en virtud de las cuales la victimización penitenciaria ha permanecido invisible a los ojos de los investigadores.

Así, en primer lugar, como ya identificamos ${ }^{1}$, conviene diferenciar dos grandes fases en el proceso evolutivo de la Victimología:

A) Victimología invisible. Abarcaría desde el primer delito conocido hasta la década de 1.940 e incluiría una etapa oscura en la que directamente no habría apenas referencias victimológicas $\mathrm{y}$, las pocas existentes, quedarían vinculadas de manera indirecta; esto es, habría otros objetos o aspectos principales, apareciendo la víctima como algo secundario - piénsese, por ejemplo, en el propio Ferri, quien defendió la necesidad de facilitar la reparación del daño, ya sea como pena sustitutiva de la pena de prisión, aplicando el trabajo del reo al pago, como pena para delitos menores, como obligación del delincuente hacia la parte dañada o como función social a cargo del Estado $^{2}$ o la tradicional hipótesis del resarcimiento, no como algo creado

\footnotetext{
${ }^{1}$ Véase, al respecto, MORILlAS FERNÁNDEZ, D. L.,; PATRÓ HERNÁNDEZ, R. M.; Y AGUILAR CÁRCELES, M. M., Victimología: Un estudio sobre la víctima y los procesos de victimización, $2^{\mathrm{a}}$ Edición, Madrid, 2014, págs. 10 y 11.

${ }^{2}$ FERRI, E. The positive school of Criminology, USA, 1968, pág. 101.
} 


\section{Doctrina y Jurisprudencia}

exclusivamente para compensar a la víctima sino más próximo a la idea retribucionista y de represión del delito-.

Ahora bien, negar la presencia de la víctima en la Historia sería absurdo pues siempre ha estado ahí, en cualquier delito, en las investigaciones sobre delincuentes (...) pero ha pasado inadvertida si bien indirectamente era tenida en consideración.

B) Victimología científica. Cabría diferenciar, a su vez, dos grandes etapas:

b1) Movimiento victimológico inicial. Dataría de la década de 1.940 y, por concretar una fecha específica, aunque no sería del todo correcto en tanto hubo aportaciones menores anteriores, la doctrina victimológica la circunscribe a 1.948 con la aparición de la obra de von $\mathrm{Hentig}^{3}$, a través de la cual logra llamar la atención sobre la necesidad de traer a un primer plano la figura de la víctima. Entre éste y Mendelsohn ${ }^{4}$, principalmente, comienzan a marcar unas bases o líneas guía sobre el fenómeno victimológico con base en las premisas de que hay una relación entre autor y víctima y unos sujetos que poseen una mayor probabilidad de ser victimizados.

b2) El reconocimiento internacional de la Victimología y su consolidación científica se produce con la celebración del I Symposium Internacional de Victimología de Jerusalén en 1973, bajo la dirección del profesor Israel Drapkin, entre los días 2 a 6 de diciembre. Semejante encuentro científico se articuló sobre cuatro grandes paneles: a) delimitación de los aspectos identificativos de la Victimología; b) la víctima; c) relaciones víctima y victimario; y d) sociedad y víctima.

El resultado de esas jornadas de trabajo fue la concreción de conceptos definitorios de Victimología y víctima, delimitación del método empleado, metodología de trabajo, establecimiento de tipologías victimales, puntos de unión entre delincuente y víctima en diversas tipologías delictivas -principalmente en los delitos contra la propiedad, de naturaleza sexual, lesiones, etc-, modelos de prevención victimal (...).

\footnotetext{
${ }^{3}$ HENTIG, H. The Criminal and his Victim, New Haven, 1948.

${ }^{4}$ MENDELSOHN, B. "La Victimologie", en Revue Francais de Psychenalise, 1958.
} 


\section{Doctrina y Jurisprudencia}

Fue tal la magnitud del éxito del Symposium que, desde entonces, se han venido celebrando de forma trianual ediciones posteriores en las que se han ido debatiendo cuestiones victimológicas actuales para cada una de las épocas en que se celebraban. Por ello, podría decirse que, conociendo el contenido de cada uno de los simposios, se determinarán las principales inquietudes victimológicas del momento y sus horizontes, por lo que resulta imprescindible vincularlos temporalmente y conocer sus hipótesis de trabajo $^{5}$. En este sentido, conviene llamar la atención sobre la ausencia de una temática específica vinculada a la victimización penitenciaria, existiendo otras generalistas en las que pudiera tener implícitamente desarrollo pero que, a efectos prácticos, no han sido convenientemente tratadas, como son los casos, por ejemplo, de la víctima en el sistema de justicia penal -III Symposium celebrado en 1979 en Munster (Alemania)-, derechos victimales en el sistema de justicia penal -XI Symposium celebrado en 2003 en Stellenbosch (Sudáfrica)- y más indirectamente, entre las temáticas tratadas, los abusos institucionales -XV Symposium celebrado en 2015 en Perth (Australia)-.

En España, la consolidación de la Victimología puede focalizarse desde dos ámbitos distintos. Por un lado, la incansable labor doctrinal ha hecho que cada vez exista un mayor número de victimólogos capaces de ahondar y profundizar en investigaciones empíricas focalizadas exclusivamente al ámbito de la víctima y no como componente adicional o secundario de otro tipo de estudios vinculados a temáticas asociadas al delito o el delincuente. En este sentido, merecen una especial consideración autores como Beristáin Ipiña, Peris Riera, Landrove Díaz, De la Cuesta Arzamendi y un largo etcétera que han contribuido con sus publicaciones teórico-prácticas al avance de la disciplina victimológica en nuestro país hasta configurar en la actualidad equipos de investigación victimológicos de primer nivel, gran parte de los cuales se han formado por sus discípulos o colaboradores. De otro, por la presencia de leyes victimales de indudable calado victimológico, que han hecho que el propio legislador implante, utilizando la citada técnica legislativa, cada vez más recursos asistenciales, sociales e incluso jurídicos vinculados al ámbito victimal. Entre todas las leyes victimales, resalto a continuación las que, en mi opinión, han podido presentar una mayor trascendencia en

\footnotetext{
${ }^{5}$ Un detallado análisis del contenido de cada uno de estos Symposium puede encontrarse en MORILLAS FERNÁNDEZ, D. L.,; PATRÓ HERNÁNDEZ, R. M.; Y AGUILAR CÁRCELES, M. M., Victimología... cit., págs. 8 y 9.
} 
la consolidación de la Victimología en nuestro país, las cuales, por otro lado, permiten vislumbrar la especial atención que prestan históricamente los poderes públicos a las distintas víctimas de delito ${ }^{6}$ :

i) Ley 7/1988, de 28 de diciembre, modificadora de las Leyes Orgánicas del Poder Judicial y de Enjuiciamiento Criminal, donde, entre otras cuestiones, se persigue una mejor atención a las víctimas del delito.

ii) Ley 19/1994, de 23 de diciembre, de Protección a Testigos y Peritos en causas criminales.

iii) Ley 35/1995, de 11 de diciembre, de Ayuda y Asistencia a Víctimas de Delitos Violentos y contra la Libertad Sexual.

iv) Ley 32/1999, de 8 de octubre, de solidaridad con las víctimas del terrorismo.

v) Ley Orgánica 1/2004, de 28 de diciembre, de Medidas de Protección Integral contra la Violencia de Género.

vi) Ley 4/2015, de 27 de abril, de Estatuto de la Víctima del Delito.

Como puede comprobarse, hasta el momento se ha otorgado una especial atención a la Victimología en esta introducción. Ello obedece a que se la considera como la principal herramienta de medición de la victimización penitenciario. Semejante afirmación se respalda por su propia definición; esto es, pese a la multitud de conceptualizaciones realizadas a nivel internacional, considero que la Victimología debe identificarse con aquella disciplina científica que posee un método empírico e interdisciplinar encargada del estudio de la víctima, capaz de presentar información relevante sobre los procesos de victimización, sus formas de actuación y prevención ${ }^{7}$.

\footnotetext{
${ }^{6}$ Un completo análisis de los textos legales presentados y otros no especificados ahora, puede encontrarse en: MORILLAS FERNÁNDEZ, D. L.,; PATRÓ HERNÁNDEZ, R. M.; Y AGUILAR CÁRCELES, M. M., Victimología... cit., págs. 295-328.
} 
Entre sus distintas funciones se encuentra la de la medición del fenómeno victimal, el cual constituye uno de los aspectos más relevantes de la Victimología ya que permite no sólo medir la población victimal sino cuantificar porcentualmente la cifra negra de ilícitos no revelados; esto es, cualquier estadística delictiva establecida al respecto únicamente recoge aquellos ilícitos conocidos mientras que a la Victimología le interesan única y exclusivamente las víctimas de delitos, hayan o no denunciado el hecho ilícito. Serrano Gómez ya se refirió a estos supuestos desconocidos como cifra oscura, englobando aquella que se conoce su existencia pero no se registra porque no hay denuncia o no hay pruebas; o criminalidad oculta, en la que la víctima desconoce que haya sufrido un delito o bien es la primera interesada en que el delito permanezca oculto $^{8}$. En mi opinión, si bien el criterio de Serrano Gómez me parece adecuado e innovador en aquella fecha, prefiero emplear la siguiente terminología a la hora de clasificar los datos:

i) Detectados. Serían aquellos que repercuten en las estadísticas en tanto se conocen de forma oficial ya que han salido a la luz pública bien mediante la correspondiente denuncia, actuaciones policiales, intervenciones judiciales (...).

ii) Detectados pero no declarados. Englobaría aquellos supuestos en los que se ha producido un delito y algún sector de la sociedad o persona ajena a delincuente y víctima conoce o sospecha su existencia pero no hace nada por su persecución o puesta en conocimiento de las autoridades correspondientes. Se trataría de un detestable caso de pasividad ciudadana que englobaría, por ejemplo, el supuesto del interno que presencia una agresión física a otro y no hace nada ni para evitarlo ni para ponerlo en conocimiento de las autoridades.

iii) No detectados. Incluye los casos en que el delito queda en el más absoluto silencio, siendo, por tanto, únicamente conocido por la víctima y el victimario, no queriendo la primera, por la razón que sea, que ese hecho sea público ni que lo

\footnotetext{
${ }^{7}$ Sobre esta y las principales definiciones existentes vid. MORILLAS FERNÁNDEZ, D. L.; PATRÓ HERNÁNDEZ, R. M.; Y AGUILAR CÁRCELES, M. M., Victimología... cit., págs. 12-37.

${ }^{8}$ SERRANO GÓMEZ, A., El costo del delito y sus víctimas en España, Madrid, 1986, pág. 47.
} 


\section{Doctrina y Jurisprudencia}

conozcan las autoridades ${ }^{9}$. Piénsese, por ejemplo, en el caso anterior con la particularidad de que la agresión se produce sin testigo, conociéndola únicamente la víctima y el victimario.

Estas dos últimas categorías, la de casos detectados pero no declarados y los no detectados, conformarían lo que se ha venido en denominar cifra negra. Así pues, de acuerdo con lo referido anteriormente, la mejor herramienta para su detección, cuantificación o aproximación radica en el uso de las estadísticas victimales, un instrumento que en la temática que nos ocupa, constituye la herramienta idónea para conocer realmente las tasas de victimización en la población reclusa.

\section{Tipos de victimización.}

La victimización comprende todo aquel proceso en virtud del cual una persona o grupo llega a convertirse en víctima. Semejante definición resulta pacífica en la doctrina si bien no lo es tanto los diversos tipos de victimización existentes, sobre los cuales se han llegado a configurar en la actualidad hasta tres categorías -primaria, secundaria y terciaria- pese a que, en mi opinión, no es del todo correcto ya que, en esta materia más que en otras, han existido determinadas prisas por incorporar tipologías, no quedando adecuadamente delimitadas; esto es, mientras la victimización primaria y secundaria comprenden unos postulados consolidados, la terciaria, pese a los intentos de reconocimiento existentes, no deja de ser más que un cúmulo de opiniones sin un criterio definido basado, fundamentalmente, en el ímpetu del avance victimológico, el cual, en esta ocasión debe resultar más pausado.

A) Victimización primaria. Se identifica con el proceso por el que una persona sufre, de modo directo o indirecto, los efectos nocivos derivados del delito o hecho traumático, independientemente de su naturaleza material o psíquica; esto es, incluiría el proceso de victimización en sí generado por el propio delito o crimen. Landrove Díaz sistematizó muy bien sus efectos: severo impacto psicológico que incrementa el daño físico o material del delito, impotencia ante la agresión, miedo a que se repita, producción de ansiedad, angustia o abatimiento, surgimiento de sensación de culpabilidad, lo que repercute en los hábitos del

\footnotetext{
${ }^{9}$ MORILlaS FERNÁNDEZ, D. L., Análisis criminológico del delito de violencia doméstica, Cádiz, 2003.
} 
sujeto alterando su capacidad de relación. Si a eso además se añade la respuesta social hacia la víctima, la cual no siempre es solidaria, genera más aislamiento ${ }^{10}$.

B) Victimización secundaria. Abarca los costes personales derivados de la intervención del sistema legal que, paradójicamente, incrementa los padecimientos de la víctima. Por ejemplo, el interrogatorio policial, el dolor causado al revivir el delito sufrido al declarar ante el Juez, el reencuentro con el agresor al acudir al Juzgado, el sentimiento de humillación experimentado en el juicio si la defensa del acusado argumenta que la responsabilidad recae en ella (...). Landrove Díaz va incluso más allá al señalar, de acuerdo con lo anterior, la víctima puede sentir que está perdiendo el tiempo, malgastando el dinero, sufre incomprensiones derivadas de la excesiva burocratización del sistema o, simplemente, sus pretensiones resultan ignoradas. Todo esto si no se producen prácticas "dudosas" tendentes a tratar a las víctimas como acusadas y sufrir la falta de tacto o la incredulidad de determinados profesionales ${ }^{11}$. Piénsese, por ejemplo, en aquéllas en las que el abogado defensor intenta tergiversar el testimonio de la víctima para lograr que no se trate de una agresión sexual con acceso carnal sino de un hecho consentido por las partes, logrando así la absolución de su defendido.

La diferencia entre victimización primaria y secundaria radica en que aquélla procede del mismo delito en sí mientras ésta resulta una consecuencia negativa del propio sistema tendente a aclarar la investigación de los hechos y el posterior proceso penal orientado a determinar la inocencia o culpabilidad del imputado.

C) Victimización terciaria. Ya se ha referido que no existe un criterio unánime al respecto sino una suma de construcciones conceptuales que, en muchos casos, no presentan vinculación unas con otras. En este sentido, para demostrar lo que acabo de afirmar, se procede a englobar las definiciones más representativas:

c1) Vinculadas al delincuente. Landrove Díaz ha sido uno de los principales defensores de semejante corriente en virtud de la cual se produciría la victimización del victimario desde una perspectiva institucional; esto es, se convertiría en víctima de unas estructuras sociales injustas que le abocarían indefectiblemente a la comisión de hechos delictivos a través de los que intentaría librarse de la marginación, la cual le impediría recurrir a medios legítimos de

\footnotetext{
${ }^{10}$ LANDROVE DÍAZ, G., La moderna Victimología, Valencia, 1998, pág. 187.

${ }^{11}$ Ibidem.
} 
emancipación. Se trataría de sujetos para los que el aparato estatal tendría reservada toda su naturaleza represiva, siendo ahí donde se generaría la verdadera victimización carcelaria donde, además de sufrir una privación de libertad, padecen sus desoladoras consecuencias ${ }^{12}$.

También se ha identificado la victimización terciaria con los padecimientos físicos y psicológicos sufridos por la familia del delincuente debido a la condena social a la que deben hacer frente debido a su vinculación familiar con el victimario.

Por su parte, semejante victimización del victimario no concluiría ahí, ya que una vez superado el período carcelario, debe enfrentarse a la victimización postpenitenciaria; esto es, tras haber superado la nocividad intrínseca de la prisión y el contagio criminógeno sufrido se encuentra un nuevo inconveniente extra muros: una sociedad cerrada, egoísta y con prejuicios que no duda en usar contra el ex recluso sus antecedentes penales negándole un puesto de trabajo, la imposición de condiciones laborales leoninas (...) convirtiéndose en una víctima sumisa y cooperante ${ }^{13}$.

c2) Asociada a la víctima o su entorno. Cabría destacar las siguientes concreciones:

c2.1) Los familiares o círculo de amistades próximo a la víctima que sufren un daño de naturaleza emocional por todo lo que se encuentra soportando la víctima.

c2.2) Terceras personas que no padecieron el proceso victimal de manera directa sino como testigos presentando secuelas derivadas del hecho victimal. Existe un debate entre los partidarios de semejante opción ya que algunos autores lo consideran victimización terciaria mientras otros la califican como victimización primaria indirecta.

c3) Posición mixta. Tamarit Sumalla y García-Pablos la identifican con el conjunto de costes de la penalización sobre quien la soporta personalmente o sobre terceros, y tendría que ver con la premisa lógica de que los costes del delito sobre las personas y la sociedad deben ser ponderados con los costes de la penalización del infractor para él mismo, terceros o la

\footnotetext{
${ }^{12}$ LANDROVE DÍAZ, G., "La victimización del delincuente", en Beristáin Ipiña, (Dir.), Victimología: VIII Cursos de Verano de San Sebastián, Vizcaya, 1990, pág. 153.

${ }^{13}$ LANDROVE DÍAZ, G., La moderna... cit., pág. 157.
} 
propia sociedad ${ }^{14}$. En otras palabras acontecería en un momento ulterior a la secundaria asociándose a la reacción de la comunidad y el modo en que lo experimenta la víctima. Por ejemplo, piénsese en el terrorismo, una vez que un terrorista es excarcelado por haber cumplido la pena de prisión acordada vuelve a la vida en sociedad siendo aclamado con honores, como si de un héroe se tratara, por un sector social, mientras la víctima sufre el aislamiento y el rechazo social hasta el punto de no poder celebrar pública y dignamente el duelo por sus feudos.

Así pues, de acuerdo con lo anterior, entiendo que los conceptos de victimización primaria y secundaria no revisten ninguna complejidad por lo que deben focalizarse como los efectos producidos del hecho ilícito en sí y los derivados del contacto de la víctima con las instituciones destinadas a la investigación y sanción del hecho delictivo, respectivamente. Sin embargo, la concreción del término victimización terciaria no resulta del todo adecuada debiendo reflexionar y profundizar aún más la doctrina victimológica para dotar de un contenido adecuado al citado vocablo. En mi opinión, debiera quedar configurado de acuerdo a las siguientes premisas ${ }^{15}$ :

i) No cabría vincularla al delincuente ya que desempeña el rol de victimario y, si bien es cierto que puede sufrir actos no deseados durante su estancia en prisión, tampoco conviene olvidar los mecanismos de denuncia con los que cuenta, al igual que cualquier ciudadano, produciéndose una victimización por un hecho ilícito acontecido en el ámbito penitenciario, no como una consecuencia derivada de la estigmatización de la propia prisión. Es más, sería más lógico recurrir a la citada terminología para agrupar a los familiares del delincuente que quedan etiquetados por la sociedad debido al comportamiento del victimario, si bien tampoco entiendo que sea la solución adecuada ya que todo proviene de la acción del delincuente y lo que aquí se enuncian son simplemente los efectos derivados del delito.

ii) Tampoco comparto las tesis derivadas de la víctima o allegados en tanto la hipótesis de la víctima-testigo creo que debe incluirse como victimización primaria indirecta mientras

\footnotetext{
${ }^{14}$ TAMARIT SUMALLA, J. M., "La Victimología: cuestiones conceptuales y metodológicas" en Baca Baldomero, Echeburúa Odriozola y Tamarit Sumalla, Manual de Victimología, Valencia, 2006, págs. 1750; GARCÍA-PABLOS DE MOLINA, A., Tratado de Criminología, Valencia, 2014.

${ }^{15}$ Esta opción ya fue defendida en el pasado. Véase, a tal efecto, MORILLAS FERNÁNDEZ, D. L.;; PATRÓ HERNÁNDEZ, R. M.; Y AGUILAR CÁRCELES, M. M., Victimología... cit., págs. 120-121.
} 


\section{Doctrina y Jurisprudencia}

que extender el supuesto a los familiares de la víctima no deja de ser sino una ampliación extensa, en cuanto al número de personas, que no hace sino caer en la indeterminación propia del concepto victimológico general de víctima.

iii) Por el contrario, sí entiendo adecuada la teoría mixta suscrita entre otros por Tamarit Sumalla y García-Pablos de vincular la victimización terciaria a un momento posterior de la secundaria, al igual que sucedía entre ésta y la primaria, creando una secuencia de victimización lógica, que acontecería sobre la reacción de la comunidad ante el cumplimiento de una sanción y la repercusión que semejantes hechos tienen en la víctima.

\section{Breve referencia a datos estadísticos penitenciarios.}

El fundamento del presente subepígrafe radica en obtener una somera visión empírica de la situación actual de los centros penitenciarios españoles con el propósito de entender y comprender mejor los procesos de victimización en el contexto de la población reclusa española y las consiguientes comparativas con otros países.

En este sentido, las variables que se presentan son muy genéricas y se vinculan a población reclusa en los centros penitenciarios españoles y su distribución por sexo, edad, nacionalidad, tipología delictiva y grado de clasificación penitenciaria ${ }^{16}$.

\footnotetext{
${ }^{16}$ Todos los datos presentados provienen de la Secretaría General de Instituciones Penitenciarias.
} 


\subsection{Tamaño de la población reclusa.}

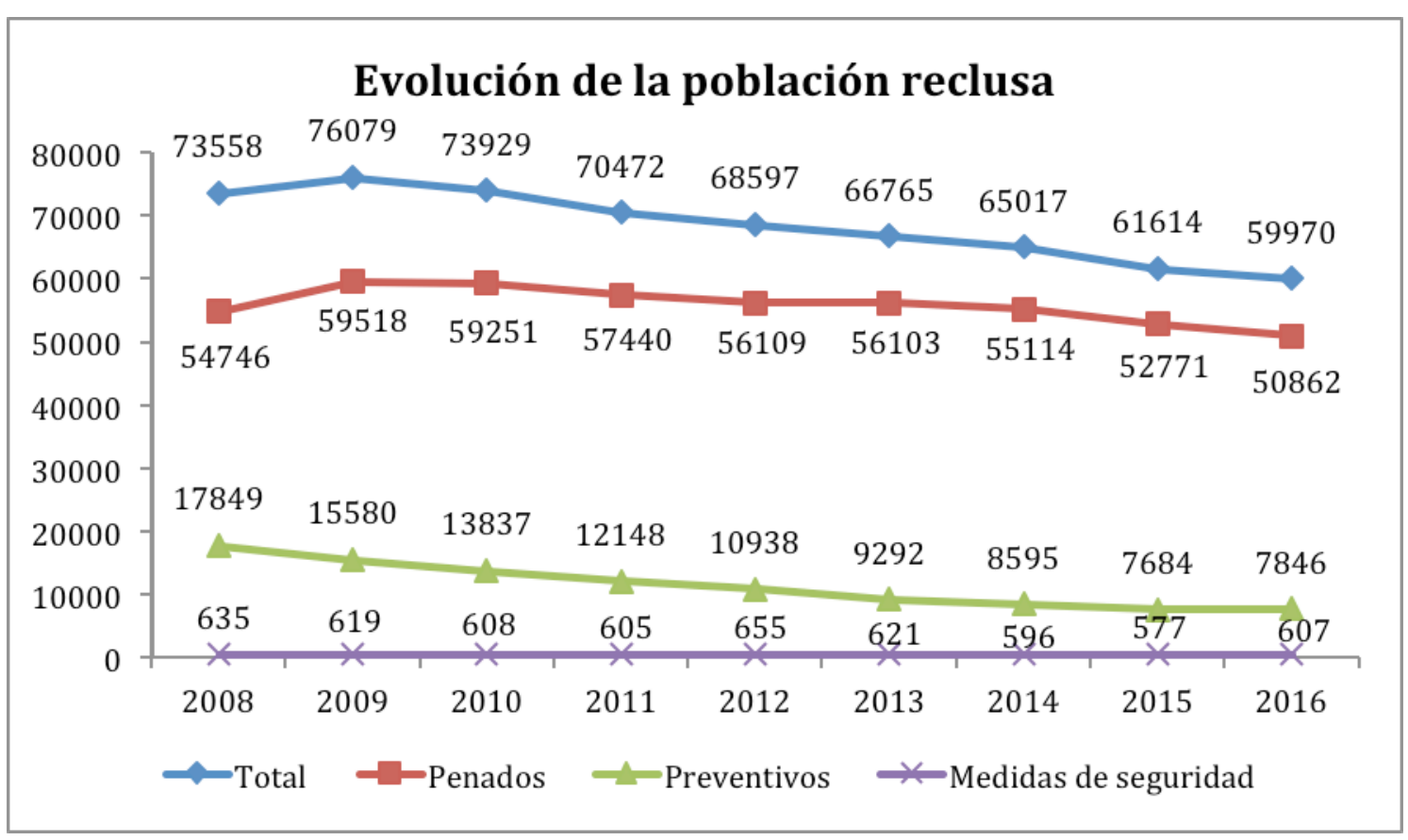

Fuente: Secretaría General de Instituciones Penitenciarias ${ }^{17}$.

Los datos cuantitativos expuestos denotan un constante descenso del tamaño de la ocupación de los centros penitenciarios españoles desde el año 2010, toda vez que en diciembre de 2009 alcanzaron los $76.079 \operatorname{reclusos}^{18}$, cifras insostenibles para la Administración española por las distintas connotaciones criminales, políticas, sociales y económicas que comporta. Así, a modo de ejemplo, el propio coste económico que

\footnotetext{
${ }^{17}$ Se ha tomado como mes referencial diciembre por ser el que cerraba el año excepto para 2016 donde se ha considerado noviembre por ser el último publicado en la fecha de cierre de este artículo. Del total de internos únicamente se han computado las variables descritas, no habiéndose particularizado las correspondientes a arrestos de fin de semana, los impagos de multa ni los que se encontraran en tránsito, en los períodos en que corresponde, ni los penados con preventivas.

18 Estas cifras deben tomarse con cierta cautela ya que también han sido modificadas en fechas posteriores a su publicación. Así, por ejemplo, en la investigación realizada en 2.014 pude constatar otra tendencia diferente a la presentada hoy día por la Secretaría General de Instituciones Penitenciarias, toda vez que el mencionado descenso de la población reclusa se produjo claramente a partir del año 2012, alcanzando en 2011 el cénit medio de 76.842 internos al año con una media de 63.446 penados, explicándose incluso semejante fenómeno por el considerable aumento de los liberados condicionales (MORILLAS FERNÁNDEZ, D. L., "Principales variables de la población reclusa en los Centros Penitenciarios españoles", en Morillas Fernández (Dir.), Criminología y ejecución de penas, Murcia, 2014, págs. 9-12).
} 
tendría que soportar el Estado comprendería una inversión de 4.945.135 euros diarios, lo que se traduciría en 1.804.974.275 euros anuales destinados al mantenimiento de los reclusos $^{19}$, si se volviera a las tasas de prisionalización de 2009, frente a los 3.898.050 euros diarios y 1.422.788.250 anuales de gasto actual, lo que supone un ahorro de 382.186 .025 euros anuales con el mero descenso del $21,18 \%$ de la población reclusa.

Sea como fuere, lo que resulta evidente es el continuo descenso de la población penitenciaria en España donde, conforme a los datos presentados, se ha reducido una quinta parte del número de internos en siete años, lo cual debe valorarse positivamente si eso ciertamente ha generado una disminución de la criminalidad en nuestro país y no se debe a otras circunstancias externas. Sin embargo, como procedo a demostrar con los siguientes gráficos, semejante premisa no se cumple, toda vez que el número de personas condenadas en las distintas anualidades es prácticamente similar -resulta algo mayor pero su diferencia no es para nada significativa, pudiendo explicarse por el leve aumento de la población- siendo incluso el porcentaje de prisionización mayor que en los años de repunte del tamaño de la población penitenciaria, si bien ha habido una disminución en el último trienio, aunque insuficiente, para contrarrestar la anterior afirmación, tal y como puede comprobarse en la siguientes gráficas:

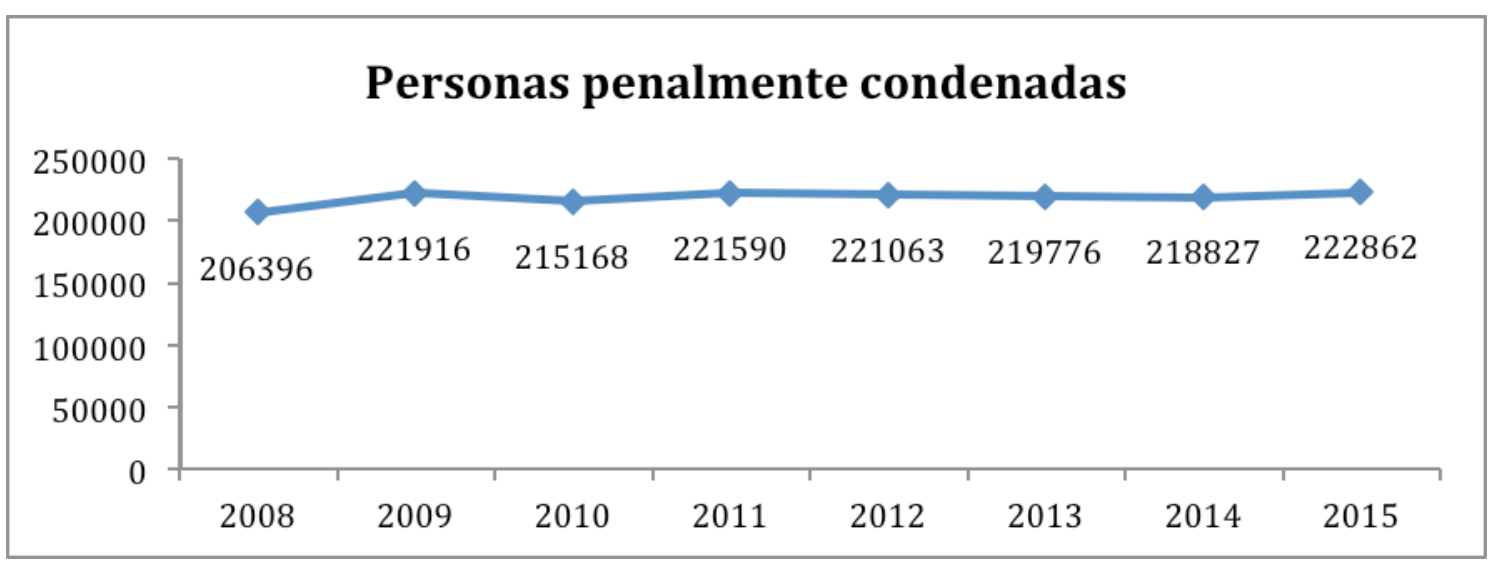

Fuente: Instituto Nacional de Estadística.

\footnotetext{
${ }^{19}$ Se ha tomado como referencia para realizar los cálculos expuestos el coste de 65 euros diarios de inversión del Estado con cada interno que se encuentra en los Centros Penitenciarios españoles.
} 


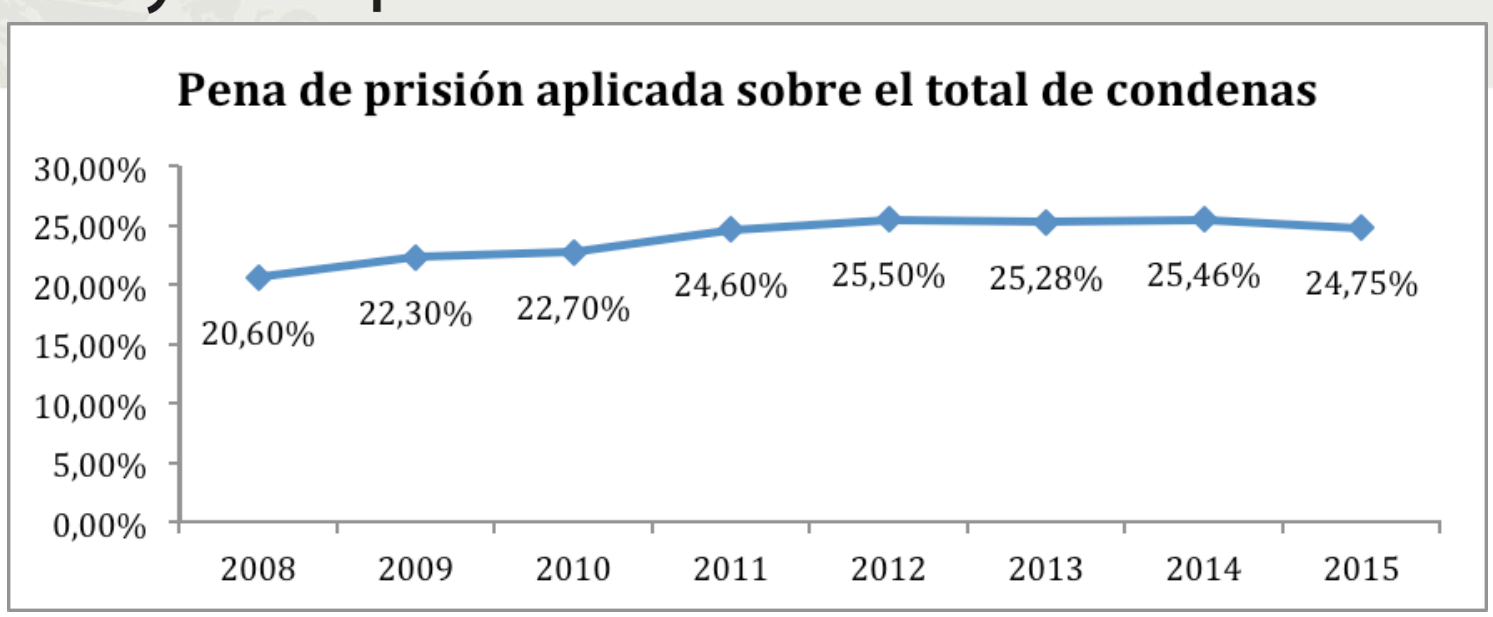

Fuente: Elaboración propia a partir de los datos del Instituto Nacional de Estadística.

La única explicación coherente que encuentro respecto al fenómeno enunciado de parámetros muy similares respecto al número de condenas y porcentaje de prisionización de las mismas pero descenso evidente de la población reclusa se reduce a un doble postulado:

i) Como ya puse de relieve en el pasado, se está haciendo un mayor uso de la libertad condicional como vía de salida de los internos de prisión, lo que reduce el tiempo de estancia de los penados en los centros penitenciarios. Este hecho fue especialmente significativo a partir de 2010 donde se potenció la salida de presos, no conforme al requisito genérico temporal de las 3/4 partes de la condena sino a través de las excepciones relativas a las $2 / 3$ partes y la de los noventa días por año cumplido una vez superada la mitad de la condena conforme a los parámetros de la anterior excepción, las cuales constituyeron el $70 \%$ de los liberados condicionales frente al $30 \%$ de la clausula genérica, lo que empezó a desvirtuar la propia configuración de la citada institución ${ }^{20}$. Pero es más, con la entrada en vigor de la reforma del Código Penal operada por Ley Orgánica 1/2015, semejante situación puede acrecentarse aún más al incorporar el legislador un nueva excepción para la obtención de la libertad condicional a partir de la mitad de la condena, no tanto por su aplicación que, por pequeña que sea, tendrá sus consecuencias estadísticas, sino por la normalización de las anteriores excepciones.

\footnotetext{
${ }^{20}$ Véase, más ampliamente, MORILLAS FERNÁNDEZ, D. L., «Libertad condicional», en La aplicación de las alternativas a la pena de prisión en España, en Morillas Cueva y Barquín Sanz (Dir.), Defensor del Pueblo, Madrid, 2013, págs. 254 y 255.
} 
ii) Por la menor entrada de sujetos en prisión, como vía alternativa de reducir el tamaño de los centros penitenciarios. Esto se logra apostando claramente por alternativas eficaces respecto a la pena de prisión, como puede ser la clara apuesta del legislador de 2015 respecto a las formas sustitutivas de la pena de prisión, a lo que contribuye también los criticadas conformidades en materia penal que garantizan la posibilidad de suspender la ejecución de la pena como contrapunto al reconocimiento de los hechos delictivos imputados, aún cuando no se hayan cometido, evitando así la hipotética entrada en prisión. Lo cierto es que los datos estadísticos hablan por sí solos $\mathrm{y}$, en este sentido, cuando se analiza la duración de la pena de prisión impuesta a los condenados, puede apreciarse claramente el fenómeno descrito y la eficacia que, en muchos de ellos, operará la suspensión de la pena:

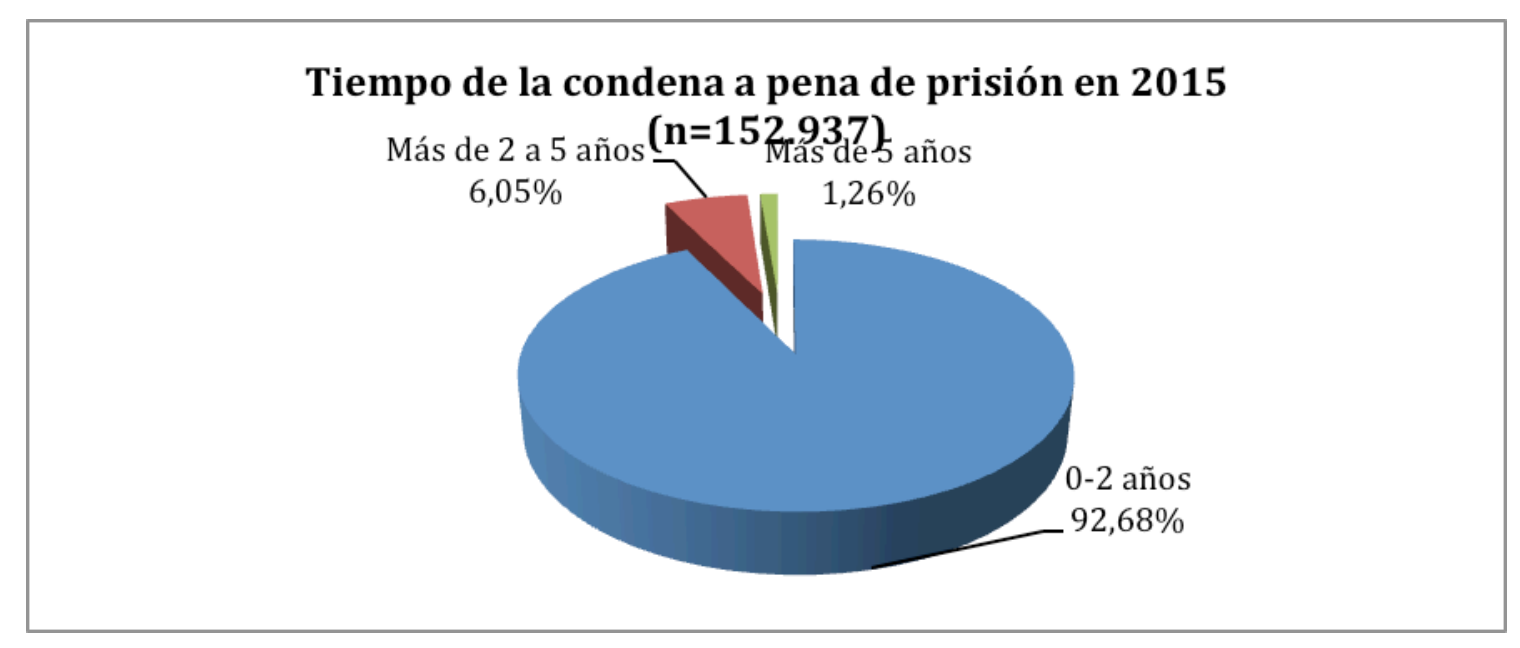

Fuente: Instituto Nacional de Estadística.

Sin embargo, realizada la correspondiente comparativa, si bien en el año 2015 se encuentra el nivel más alto de condenas a pena de prisión hasta dos años, las diferencias en el último quinquenio no resultan para nada significativas resultando una diferencia de 2,4 puntos porcentuales entre el máximo y el mínimo del período de tiempo referido, lo cual no puede explicar, ni mucho menos, el fenómeno tan acrecentado de bajada del número de internos. 


\begin{tabular}{|c|c|c|c|c|c|}
\hline & 2011 & 2012 & 2013 & 2014 & 2015 \\
\hline $\begin{array}{c}\text { \% de condenas a penas de prisión de hasta } \\
\text { dos años }\end{array}$ & $90,2 \%$ & $91,3 \%$ & $91,6 \%$ & $92,3 \%$ & $92,7 \%$ \\
\hline
\end{tabular}

Fuente: Elaboración propia a partir de los datos del Instituto Nacional de Estadística.

\subsection{Género.}

Tradicionalmente se ha vinculado la delincuencia con el sexo masculino, habiendo buscado la Criminología explicaciones específicas al citado fenómeno ${ }^{21}$ si bien la existencia de unos parámetros porcentuales para nada normales, máxime cuando, como denotan las estadísticas de los últimos quince años, la variación porcentual es mínima, de escasas décimas, en las comparativas anuales realizadas. En este sentido, la situación en los centros penitenciarios españoles en la actualidad no difiere de la imagen tradicional de representatividad de uno y otro sexo, manteniéndose en el intervalo 92$8 \%$.

\footnotetext{
${ }^{21}$ Redondo Illescas y Garrido Genovés han compilado las explicaciones más plausibles otorgadas al respecto sobre premisas de naturaleza cultural, biológica, moral, de socialización, resistencia al estrés o diferentes oportunidades para delinquir (REDONDO ILLESCAS, S. y GARRIDO GENOVÉS, S., Principios de Criminología, Valencia, 2013, págs, 369-376. Anteriormente, GARRIDO, V., STANGELAND, P. Y REDONDO, S., Principios de Criminología, Valencia, 2006, págs. 316-328). No obstante, algunas han sido descartadas por el propio paso del tiempo y la invariabilidad de los citados porcentajes. En este sentido, por ejemplo, la mayor oportunidad para delinquir o las premisas socioculturales que vinculaban a la mujer a un ámbito más doméstico que social, respecto del varón, con la consiguiente disminución de la oportunidad para delinquir han quedado desfasadas y relegadas en el tiempo con la incorporación de la mujer a las distintas esferas sociales, culturales, laborales (...) que , de ser así, hubieran propiciado una disminución de las referidas tasas, las cuales pese a ello, continúan impertérritas.
} 
Sexo de la población reclusa a fecha de noviembre de $2016(n=59.970)$

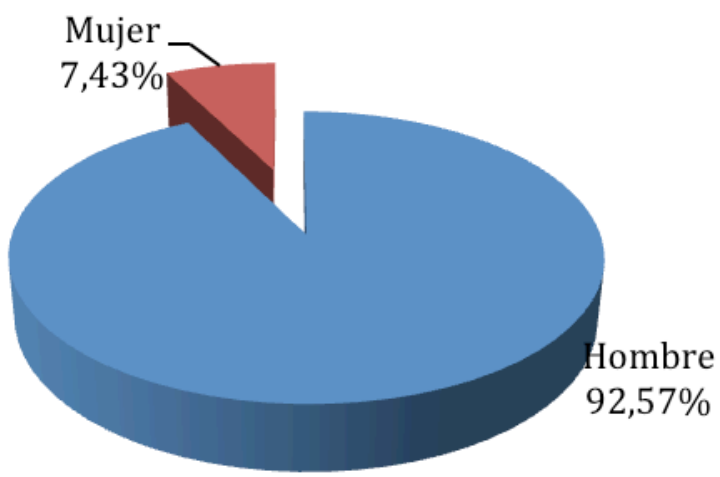

Fuente: Secretaría General de Instituciones Penitenciarias.

Este hecho podría plantear la hipótesis de asociar la delincuencia al género masculino predominantemente si bien pudiera existir al respecto algún tipo de sesgo fundado en la posible existencia de un mayor número de condenas a pena de prisión, por una u otra razón, a la población masculina respecto de la femenina. Sin embargo, una vez más, semejante hipótesis debe ser rechazada ya que, si se toma como referente la población condenada durante el año $2015^{22}$ por los Tribunales penales españoles, se observa la presencia mayoritaria de condenados varones respecto a mujeres, si bien no en tasas no tan elevadas, sigue constituyendo una diferencia sustancial que, sin embargo, al contrario que en la población reclusa, tiende a disminuir, siquiera muy levemente con el transcurso de los años ${ }^{23}$ :

\footnotetext{
${ }^{22}$ Constituye la última anualidad publicada por el Instituto Nacional de Estadística.

${ }^{23}$ A modo de ejemplo, en el año 2012 la relación porcentual era de 89,1\% varones y 10,9\% mujeres (véase, más ampliamente, MORILLAS FERNÁNDEZ, D. L., "Variables..." cit., págs. 22-26).
} 
Sexo de la población condenada en 2015

Muje( $\mathbf{n}=\mathbf{2 2 2 . 8 6 2})$

$14,35 \%$

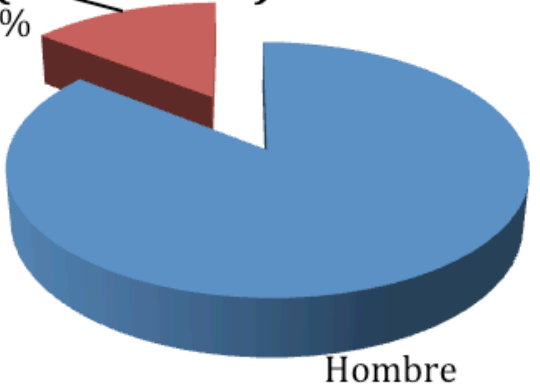

$85,65 \%$

Fuente: Instituto Nacional de Estadística

\subsection{Edad.}

La variable edad ha sido estudiada por la doctrina criminológica como forma o mecanismo de explicar la delincuencia y, en el ámbito que ahora interesa, presenta importantes connotaciones que necesariamente deben ser contextualizadas.

\section{Edad de la población penada en prisión en noviembre de $2016(n=50.861)$}

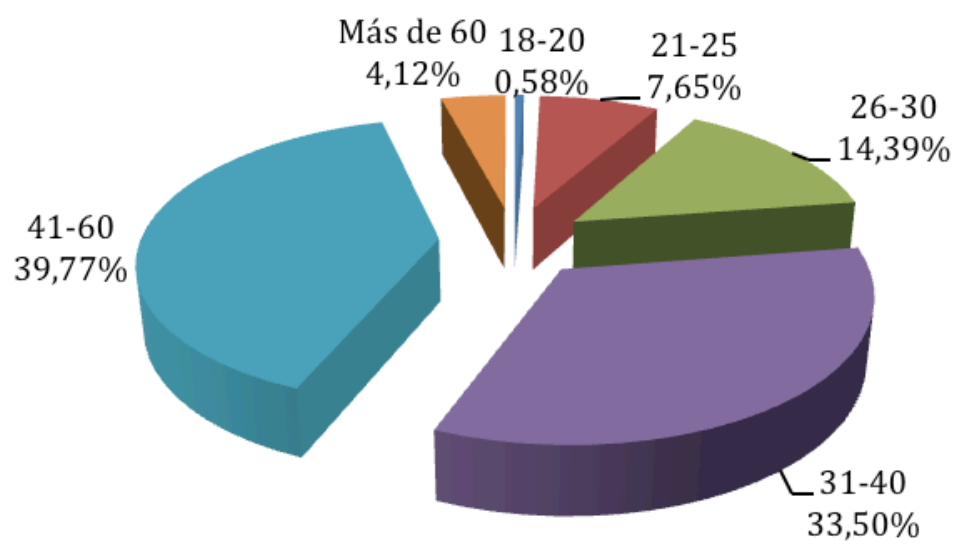

Fuente: Secretaría General de Instituciones Penitenciarias.

El anterior reparto porcentual entre franjas de edad desvela un importante equilibrio entre las franjas que van desde la mayoría de edad a los cuarenta años, 
instante en el que empiezan a disminuir porcentualmente los grupos de edad. No obstante, lo anterior es una mera traslación cuantitativa de datos que necesariamente debe ir vinculada al nivel de representatividad de la sociedad en general, lo cual puede permitir ver si existe una sobrerrepresentación que explique los porcentajes referidos. En este sentido, la comparativa quedaría estructurada de la siguiente forma:

\begin{tabular}{|c|c|c|}
\hline GRUPO DE EDAD & $\begin{array}{c}\text { \% POBLACIÓN } \\
\text { GENERAL }\end{array}$ & \% PRISIÓN \\
\hline $\mathbf{1 8 - 2 0}$ & $2,8 \%$ & $0,57 \%$ \\
\hline $\mathbf{2 1 - 2 5}$ & $5 \%$ & $7,65 \%$ \\
\hline $\mathbf{2 6 - 3 0}$ & $5,56 \%$ & $14,38 \%$ \\
\hline $\mathbf{3 1 - 4 0}$ & $15,19 \%$ & $33,5 \%$ \\
\hline $\mathbf{4 1 - 6 0}$ & $30,2 \%$ & $39,7 \%$ \\
\hline Más de 60 & $23,24 \%$ & $4,11 \%$ \\
\hline
\end{tabular}

Fuente: Elaboración propia a partir de los datos del INE y de la SGIP.

Del análisis de los datos expuestos pueden extraerse las siguientes conclusiones:

i) Los intervalos de edad que sufren una menor prisionización se encuentran en los extremos inicial y final, los cuales aparecen infrarrepresentados en los centros penitenciarios, lo cual se debe, respecto a aquél, a la eficacia de la suspensión de la pena sobre el primer delito cometido, conforme a lo establecido legalmente; mientras, en el segundo caso, la vinculación biológica de las personas de más de sesenta años hace el resto.

\footnotetext{
${ }^{24}$ Elaboración propia a partir de los datos del Instituto Nacional de Estadística. Se ha tomado como población muestral los sujetos de entre dieciocho años, por constituir el límite mínimo de la población reclusa, y la franja "110 años y más” por constituir el máximo de edad en la población.
} 
ii) Aunque la representatividad del resto de niveles es mayor en prisión que en la sociedad en general, conviene destacar la relevancia del intervalo entre los veintiséis y los cuarenta años, donde se concentraría el mayor volumen de población delincuente, resaltando particularmente la que va de los veintiséis a los treinta, donde casi se triplica la representatividad del grupo en la población general, una cifra alarmantemente alta.

\subsection{Nacionalidad.}

Resulta muy sorprendente que una de las principales variables, en cuanto a resultados, que merecería una mayor atención y estudio por parte de los investigadores y poderes públicos, goce cada vez de una menor transparencia, resultando más complejo encontrar datos fiables al respecto. En este sentido, la página web de la Secretaría General de Instituciones Penitenciarias ha dejado de publicar directamente los niveles de representatividad del citado colectivo dentro de la población reclusa como variable independiente $^{25}$, si bien pueden obtenerse los datos actualizados recurriendo a variables accesorias como la distribución por género de la población reclusa extranjera y su homogéneo genérico. En este sentido, los niveles de representatividad, con fecha de noviembre de 2016, serían los siguientes ${ }^{26}$ :

\section{Nacionalidad de la población reclusa $(n=59.970)$}

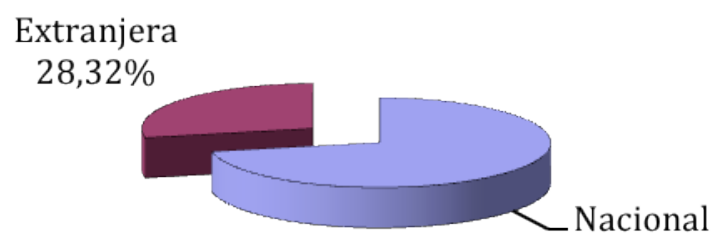

$71,68 \%$

Como ha podido comprobarse, el dato es ciertamente alarmante si se tiene presente que la representatividad de la población extranjera mayor de edad en el

\footnotetext{
${ }^{25}$ El último dato accesible radica del año 2012.

${ }^{26}$ Elaboración propia a partir de los datos de los datos parciales de la Secretaría General de Instituciones Penitenciarias.
} 


\section{Doctrina y Jurisprudencia}

territorio español se encuentra en torno al $10 \%^{27}$, lo cual significa que la población carcelaria extranjera triplica la tasa media representativa. Sin embargo, este hecho no es nuevo sino que es el resultado de un proceso evolutivo que se ha consolidado en los últimos años la tendencia de representatividad de la población reclusa extranjera en los centros penitenciarios españoles ha ido incrementándose porcentualmente con el paso de los años a un ritmo bastante más acelerado que la nacional, llegando a triplicarse cuantitativamente en un período de diez años. No obstante, semejante fenómeno encuentra una desaceleración y cambio de tendencia a partir del año 2011, volviéndose en la actualidad a los niveles de 2005 y 2006.

Estos datos debieran haber abierto un profundo debate sobre los mecanismos de atención, recursos sociales y demás que afectan a la población reclusa extranjera y que, en no pocas ocasiones, no cumplen adecuadamente con los objetivos con los que inicialmente fueron diseñados, siendo necesaria una nueva revisión y potenciación de los medios de control social informal en este sentido vinculándolos, aún más si cabe, hacia nuevas políticas de actuación e intervención de naturaleza social.

\subsection{Tipología delictiva.}

Lo primero que debe tenerse presente es que aún, en noviembre de 2016, hay 226 personas cumpliendo condena por delitos cometidos conforme al Texto Refundido de Código Penal de 1973 conforme a las siguientes tipologías delictivas:

\footnotetext{
${ }^{27}$ De acuerdo con la base de datos del Instituto Nacional de Estadística, con fecha de 1 de julio de 2016, era de un $9,47 \%$.
} 


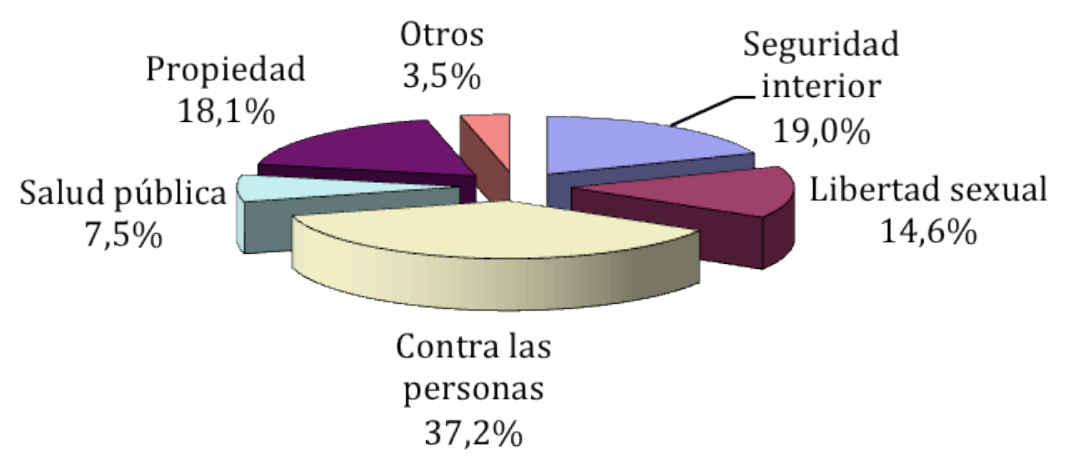

Fuente: Secretaría General de Instituciones Penitenciarias.

En cuanto al Código Penal de 1995, tradicionalmente las tipologías delictivas más habituales entre la población reclusa han sido las vinculadas a delitos contra el patrimonio y el orden socioeconómico y salud pública. Sin embargo, esto no quiere decir que sean los más habituales cometidos en nuestro país sino aquéllos más representativos en cuanto a que la consecuencia jurídica conlleva una pena de prisión. En este sentido, debe tenerse muy presente que las categorías que se enunciarán a continuación responden a las siguientes premisas: i) la pena o una de las penas por las que se encuentra cumpliendo condena el interno es la de prisión; ii) no se contemplan los supuestos en los que se ha aplicado la suspensión o sustitución de la pena.

En definitiva, lo que se presenta a continuación es una ponderación de los delitos por los que los internos se encuentran cumpliendo una pena de prisión ${ }^{28}$ :

\footnotetext{
${ }^{28}$ Datos obtenidos de la Secretaría General de Instituciones Penitenciarias.
} 


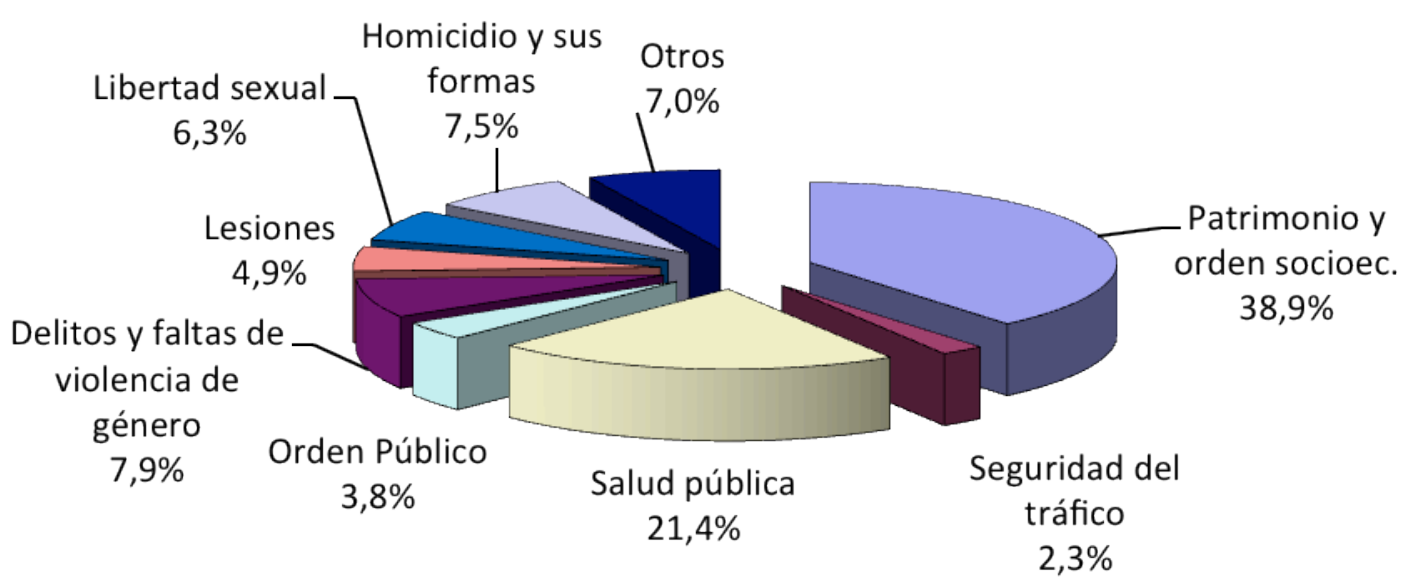

De acuerdo con lo anterior, pueden establecerse las siguientes premisas:

A) La sistemática utilizada no parece la más adecuada pues la estructuración de las categorías no es uniforme, optando unas veces por tipos delictivos concretos y otras por rúbricas excesivamente extensas y donde se encuadran decenas de figuras delictivas que distorsionan los resultados a un nivel más bajo -véase, por ejemplo, los delitos contra el patrimonio y el orden socioeconómico- ${ }^{29}$.

B) Los delitos contra el patrimonio y el orden socioeconómico constituyen el $38,9 \%$ y, si les sumamos los relativos a salud pública, la cifra se dispara al 60,3\% del

\footnotetext{
${ }^{29}$ Del mismo modo, como ya manifesté en su momento, llama la atención la utilización de rúbricas desfasadas en el tiempo, como los denominados "delitos contra la seguridad del tráfico", terminología modificada con la reforma del Código Penal operada por Ley Orgánica 15/2007, de 30 de noviembre, en virtud de la cual se acotó la referencia "delitos contra la seguridad vial"; o la inclusión expresa de una categoría de delitos y faltas de violencia de género, aspecto este último curioso a efectos estadísticos toda vez que los tipos penales que pudieran incluirse bajo la citada rúbrica se encuentran sistemáticamente incluidos entre los delitos de lesiones, contra la libertad o contra la integridad moral, principalmente, piénsese, por ejemplo, en un delito del artículo 153.1 con ingreso en prisión, ¿dónde se computa este caso, como delito de lesiones o en la referencia específica a delitos contra la violencia de género?-. Del mismo modo, carece de sentido la referencia a "faltas de violencia de género", toda vez que no hay faltas vinculadas a la citada descripción ya que, en base a la reforma operada en virtud de la Ley Orgánica $1 / 2004$, de 28 de diciembre, cuando la víctima de alguno de los hechos constitutivos de falta fuera o hubiese sido esposa, o mujer que esté o haya estado ligada al autor por una análoga relación de afectividad aún sin convivencia (...), la calificación del hecho se transformará en delito, de acuerdo con las disposiciones normativas existentes al efecto. Pero es más, la única descripción que pudiera encajar en la citada rúbrica sería las del derogado artículo $620.2^{\circ}$, referido a las víctimas del 173.2 , situación que excede del concepto de violencia de género ya que reitero, los hechos se transforman en delito (MORILLAS FERNÁNDEZ, D. L., "Variables..." cit., págs. 15-17).
} 


\section{Doctrina y Jurisprudencia}

total de ilícitos penales por los que los penados se encuentran cumpliendo una pena de prisión, si bien la citada estadística no permite profundizar en la naturaleza específica de los tipos penales, lo cierto es que seis de cada diez internos lo hace por una de estas categorías delictivas.

\subsection{Grado de tratamiento.}

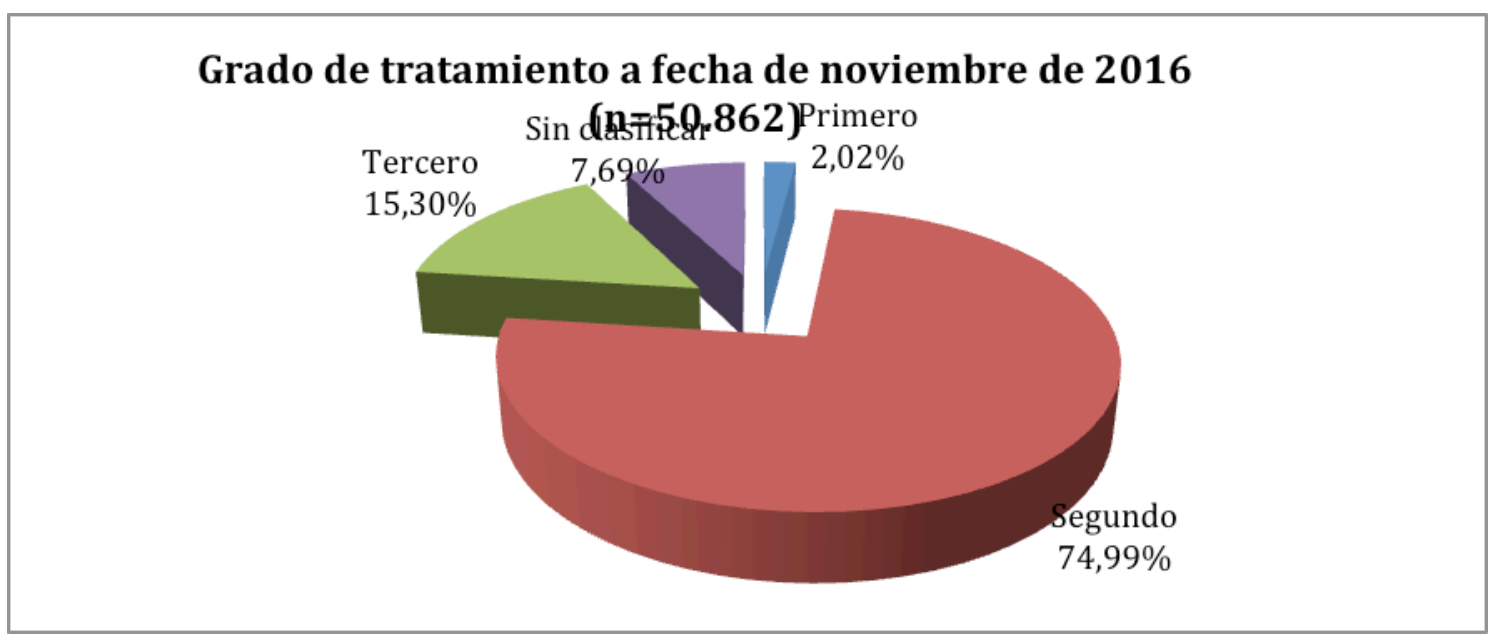

Fuente: Secretaría General de Instituciones Penitenciarias.

De acuerdo con el gráfico anterior, deben tenerse en cuenta los siguientes aspectos:

A) La clasificación en segundo grado es el estadio más habitual en los Centros Penitenciarios españoles, aplicándosele a los internos el régimen ordinario o genérico de vida en prisión.

B) El tercer grado constituye la segunda tipología más habitual de clasificación de los internos y conlleva la aplicación del régimen abierto, situación más flexible que el ordinario, en tanto, entre otras circunstancias, conlleva:

b1) El cumplimiento de la pena en Centros Abiertos o de Inserción Social, Secciones Abiertas o Unidades Dependientes. 
b2) Potenciación de las capacidades de inserción social positiva que presentan los penados clasificados en tercer grado, realizando las tareas de apoyo y de asesoramiento y la cooperación necesaria para favorecer su incorporación progresiva al medio social. Todo ello basado en: i) atenuación de las medidas de control, sin perjuicio del establecimiento de programas de seguimiento y evaluación de las actividades realizadas por los internos dentro y fuera del Establecimiento; ii) autorresponsabilidad, mediante el estímulo de la participación de los internos en la organización de las actividades; iii) normalización social e integración, proporcionando al interno, siempre que sea posible, atención a través de los servicios generales de la comunidad para facilitar su participación plena y responsable en la vida familiar, social y laboral; iv) prevención para tratar de evitar la desestructuración familiar y social; y v) coordinación con cuantos organismos e instituciones públicas o privadas actúen en la atención y reinserción de los reclusos, promoviendo criterios comunes de actuación para conseguir su integración en la sociedad.

b3) Salidas del establecimiento para desarrollar las actividades laborales, formativas, familiares, de tratamiento o de otro tipo, que faciliten su integración social.

b4) Salidas de fines de semana (...).

C) El primer grado constituye el régimen más duro de cumplimiento de la pena en una institución penitenciaria ya que conlleva una restricción de derechos. Por las propias premisas del sistema penitenciario español es aquel que se trata de evitar en la medida de lo posible por las consecuencias que conlleva para el penado, configurándose como el menos utilizado sobre la población reclusa, siendo una cantidad ínfima de internos los que se encuentran en el citado nivel, procediéndose a su clasificación en aquellos casos en los que, bien inicialmente, bien por una involución en su personalidad o conducta, se consideren extremadamente peligrosos o manifiestamente inadaptados a los regímenes ordinario y abierto. Entre sus características, a modo de ejemplo, se encuentra el hecho de: i) ubicación en Centros o módulos de régimen cerrado o en departamentos especiales ubicados en Centros de regímenes comunes, con absoluta separación del resto de la población reclusa; ii) cumplimiento en celdas individuales, caracterizándose por una limitación de las actividades en común de los internos y por un 
mayor control y vigilancia sobre los mismos, exigiéndose, de manera especial, el acatamiento de cuantas medidas de seguridad, orden y disciplina elabore el Consejo de Dirección, previo informe de la Junta de Tratamiento.

\section{VICTIMIZACIÓN PENITENCIARIA}

Como ya he referido, aunque un sector doctrinal ha vinculado al delincuente con la victimización terciaria, en mi opinión, no cabría incluirla en la citada categoría, debiendo reconducir los casos de victimización penitenciaria a la esfera primaria, independientemente de la naturaleza física o jurídica del victimario, toda vez que incluiría a la persona que sufre, directa o indirectamente, los efectos nocivos derivados de un delito o acto ilícito, independientemente de su naturaleza material o psíquica. En este sentido, como ha señalado Hikal, la victimología penitenciaria tendría como sujetos de estudio, aquellos reclusos que son sometidos a un proceso penitenciario por el tiempo que fuera, desde la prisión preventiva hasta su estancia prolongada con o sin sentencia $^{30}$.

En cuanto a las tipologías de victimización penitenciaria existentes distinguiría entre dos hipótesis perfectamente delimitadas: la institucional y la primaria propiamente dicha.

A) Victimización institucional. Se trataría del supuesto de victimización por parte de la propia Administración en tanto incluiría todos aquellos casos en los que no se observen las garantías o derechos reconocidos legalmente a los internos, tratándose, en consecuencia, de una clara dejación de funciones garantistas de las que debe

\footnotetext{
${ }^{30}$ HIKAL, W., "El presente y futuro de la Victimología: Ciencia, Filosofía y Prevención", en Revista de Criminologia e Ciéncias Penitenciárias, Año 1, número 1, 2011, pág. 4. Recurso electrónico disponible en: http://www.sap.sp.gov.br/download_files/pdf_files/copen/edicao-01/09\%20-\%20Artigo\%20D.I.\%20$\% 20 \mathrm{El} \% 20$ presente $\% 20 \mathrm{y} \% 20$ futuro $\% 20 \mathrm{de} \% 201 \mathrm{a} \% 20$ Victimologia.pdf
} 
responder activamente la Administración penitenciaria, causando su inobservancia perjuicios en el interno ${ }^{31}$.

En el caso del ordenamiento jurídico español, entendería generada la citada victimización en aquellos casos en los que no se respetara el artículo 4 del Reglamento Penitenciario, en el cual se reconocen los derechos y deberes de los internos. En relación a los primeros, el parágrafo 4.2 del citado texto legal reconoce los siguientes: i) vida, integridad y salud; ii) dignidad e intimidad; iii) ejercicio de derechos civiles, políticos, sociales, económicos y culturales; iv) al tratamiento penitenciario y a las medidas programadas con el fin de asegurar su éxito; v) a las relaciones con el exterior previstas en la legislación; vi) a un trabajo remunerado, dentro de las posibilidades de la Administración penitenciaria; vii) a acceder y disfrutar de las prestaciones públicas que pudieran corresponderles; viii) a los beneficios penitenciarios previstos; ix) a participar en las actividades del Centro; $\mathrm{x}$ ) a formular peticiones y quejas antes las autoridades penitenciarias, judiciales, Defensor del Pueblo y Ministerio Fiscal, así como dirigirse a las autoridades competentes y utilizar los medios de defensa de sus derechos e intereses legítimos contemplados en el Capítulo V del Título II del Reglamento Penitenciario; xi) recibir información personal y actualizada de su situación procesal y penitenciaria.

En términos muy parecidos, desde una perspectiva doctrinal, podrían identificarse los supuestos de victimización institucional. En este sentido, según López Melero, los derechos fundamentales de los reclusos se vertebrarían sobre el concepto de dignidad y su dimensión moral, debiendo reconocerse los siguientes derechos: i) civiles e individuales de los presos, tales como la vida, integridad física y moral, intimidad y libertad religiosa; ii) relativos a la seguridad, donde incluiría la seguridad propiamente dicha -observación de los reclusos, recuentos, intervenciones, cacheos, etc.- y comunicaciones; iii) de naturaleza política, tales como reunión y manifestación, asociación, participación política, petición, acceso a las funciones públicas y resto de derechos políticos y la defensa en los propios Centros Penitenciarios; iv) sociales, como

\footnotetext{
${ }^{31}$ Este tipo de victimización ha venido identificándose como un proceso de victimización generado por instituciones totales. Sobre su contenido, características y particularidades, véase VARONA, G., "Procesos de la victimización y desvictimización en las instituciones totales", en Tamarit y Pereda (Coord.), La respuesta de la Victimología ante las nuevas formas de victimización, Madrid, 2014, págs. 247-269.
} 
la protección de la salud -exámenes médicos, prestaciones de enfermería, dependencias para trastornos mentales o toxicómanos-, acceso al sistema laboral -trabajo penitenciario- o derecho a la educación ${ }^{32}$.

En consecuencia con lo anterior, se entendería generada este tipo de victimización en sentido negativo; esto es, cuando no se apreciasen o denegasen, sin causa legal, los citados derechos por causas imputables a la Administración Penitenciaria.

A nivel internacional, las dos principales causas de victimización penitenciaria institucional se vinculan al ámbito de la masificación de las prisiones y la asistencia sanitaria.

a1) Masificación. Constituye uno de los grandes problemas de las prisiones sudamericanas. Las imágenes hablan por sí solas y es que un exceso de población penitenciaria conlleva además problemas de otro tipo vinculado principalmente a la higiene, seguridad, alimentación (...) lo que convierte a los centros penitenciarios en auténticos caldos de cultivo de conflictos por la especial dificultad de convivencia de los internos, llegando en los casos más extremos a hacer prácticamente inviable el adecuado desarrollo de las tareas de los propios funcionarios, quienes llegan a perder el propio control del centro que pasa a manos de colectivos, bandas y grupos organizados de internos del propio centro, que son quienes marcan el régimen y estilo de vida del interior de la prisión.

A nivel europeo, el Consejo de Europa viene estudiando de manera periódica en sus Informes Space $^{33}$ la densidad de las prisiones por capacidad, volumen de internos y tasas de masificación, entre otras variables. En las siguientes gráficas se exponen los

\footnotetext{
${ }^{32}$ LÓPEZ MELERO, M., Los derechos fundamentales de los reclusos, Madrid, 2015.

${ }^{33}$ El Space I referido a 2012, el II a 2014 mientras el último publicado el 2015\&2016 incluye los períodos referidos en su título. Recursos electrónicos disponibles en: http://wp.unil.ch/space/
} 
datos de los principales países europeos ${ }^{34}$ midiendo la variable genérica de masificación de las prisiones de los respectivos estados ${ }^{35}$ :

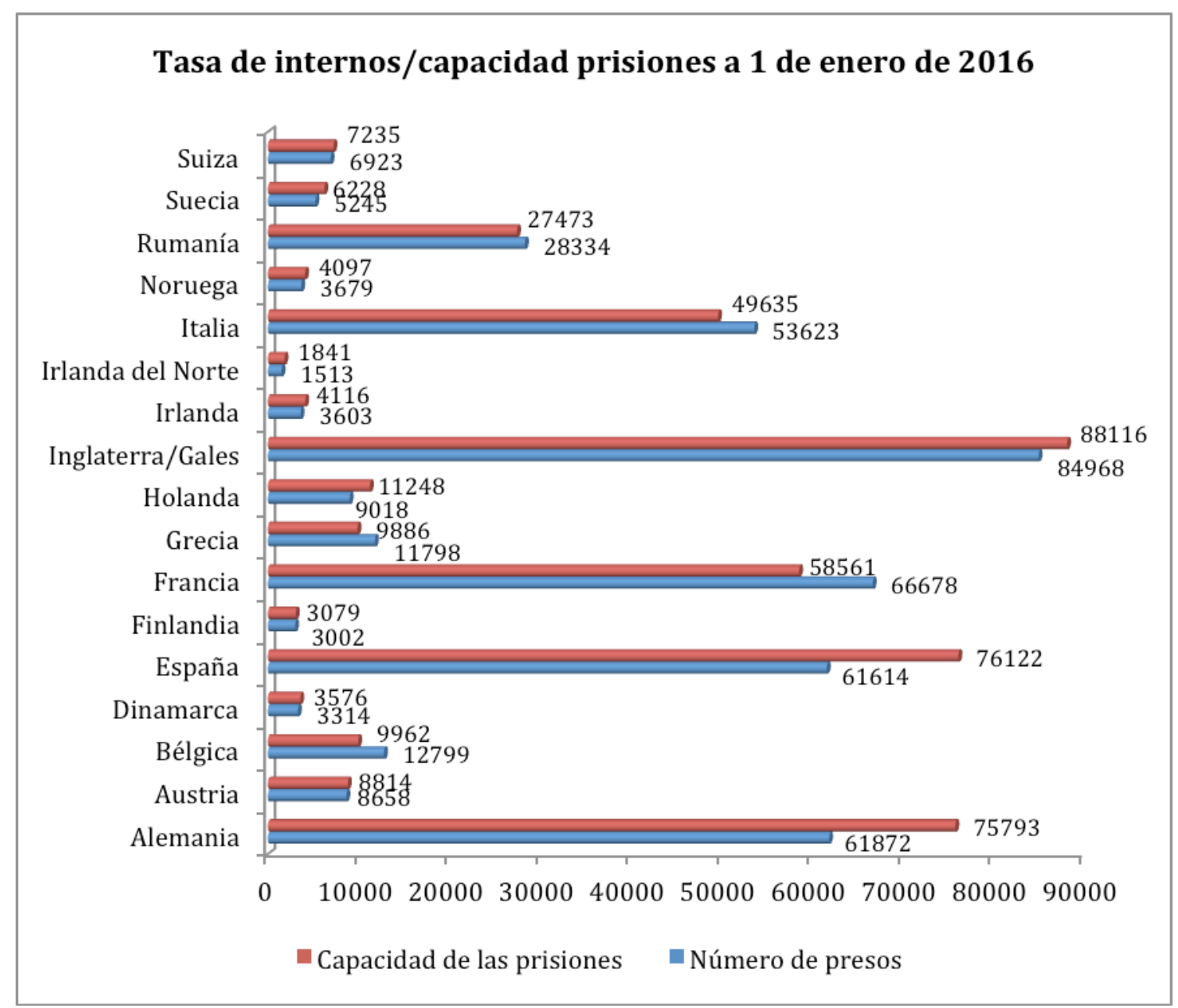

${ }^{34}$ Un análisis de los datos penitenciarios relativos al Space I y II puede encontrarse en MORILLAS CUEVA, L., ¿¿Pasa la legitimación de la pena de prisión en una sociedad democrática por una Política Criminal reduccionista?", en Revista Internacional de Doctrina y Jurisprudencia, vol. 8, 2014, págs. 3033.

35 Datos obtenidos del Informe Space 2015\&2016. Recurso electrónico disponible en: http://wp.unil.ch/space/space-i/prison-stock-on-1st-january/prison-stock-on-01-jan-2015-2016/

Al no estar disponibles los datos de Alemania, Italia y Suiza con fecha de 1 de de enero de 2016, se han utilizado los de 1 de enero de 2015, si bien la diferencia entre ambos períodos no se estima relevante no siendo superior o inferior, en ningún caso, al $6 \%$ de las tasas referidas. 
Revista Internacional de

\section{Doctrina y Jurisprudencia}

\begin{tabular}{|c|c|c|}
\hline PAÍS & $\begin{array}{l}\text { NIVEL DE MASIFICACIÓN } \\
\text { POR CADA } 100 \text { CELDAS }\end{array}$ & $\begin{array}{c}\text { TASA DE INTERNOS POR } \\
\text { CADA } 100.000 \\
\text { HABITANTES }^{36}\end{array}$ \\
\hline Alemania & 81,6 & 76,2 \\
\hline Austria & 92,5 & 101,3 \\
\hline Bélgica & 111,1 & 101,3 \\
\hline Dinamarca & 92,7 & 90,7 \\
\hline España & 80,9 & 143,1 \\
\hline Finlandia & 91 & 54,4 \\
\hline Francia & 113,9 & No disponible \\
\hline Grecia & 119,3 & 108,7 \\
\hline Holanda & 80,2 & No disponible \\
\hline Inglaterra/Gales & 96,4 & No disponible \\
\hline Irlanda & 87,5 & 76,6 \\
\hline Irlanda del Norte & 82,2 & No disponible \\
\hline Italia & 108 & 88.2 \\
\hline Noruega & 90,2 & 70,3 \\
\hline Rumanía & 103,1 & 151,8 \\
\hline Suecia & 84,2 & 55,4 \\
\hline Suiza & 95,7 & 84 \\
\hline
\end{tabular}

\footnotetext{
${ }^{36}$ Por no estar aún disponible la citada tasa se presenta con fecha de 1 de enero de 2015.
} 
De acuerdo con los datos de la anterior gráfica, pueden extrapolarse las siguientes conclusiones:

i) Un $25 \%$ de los países europeos presentan sus prisiones masificadas. Los casos más relevantes son los de Macedonia (136), Grecia (119,3), Albania (114,7), Francia $(113,9)$, Bélgica $(111,1)$, Italia $(108)$, Montenegro $(108,5)$, Serbia $(106,4)$, Eslovenia $(105,4)$ o Rumanía $(103,1)$, donde hay auténticos problemas de hacinamiento penitenciario con las consecuencias ya mencionadas que subyacen de manera conjunta con lo anterior.

ii) España presenta una posición holgada respecto a la masificación de las prisiones, todas vez que se encuentra 20 puntos por debajo del citado nivel, encontrándose pareja a Alemania u Holanda y en mejor situación que Italia, Francia o Inglaterra. Sin embargo, semejante afirmación debe ser matizada y contextualizarla en el entorno en el que nos encontramos ya que esta situación no ha sido tradicionalmente ni mucho menos así.

El punto de partida del fenómeno actual hay que encontrarlo en los Informes llevados a cabo por el Comité Europeo para la Prevención de la Tortura y de las Penas o Tratos Inhumanos o Degradantes, donde se puso manifiesto la masificación existente en los Centros Penitenciarios españoles, la cual llegó a alcanzar el 143\% en 2007, por lo que se instó al Estado español a que acotara las medidas necesarias para solucionar el citado problema ${ }^{37}$. Así, entre otras, se fomentó la construcción de nuevos centros penitenciarios, además de los ya proyectados, dentro del Programa de Construcción de Prisiones 2005-2012. Sin embargo, el resultado de la citada actuación no fue la más deseada, toda vez que la población carcelario disminuyó de manera ostensible aumentándose de manera desproporcional el número de plazas en las prisiones españoles, lo cual ha llevado a una situación indeseada consistente en que existen centros penitenciarios españoles de nuevas construcción cerrados y otros abiertos de manera parcial, toda vez que compaginan los módulos abiertos con otros cerrados y, por

\footnotetext{
${ }^{37}$ Los distintos informes elaborados por el Comité Europeo para la Prevención de la Tortura y de las Penas o Tratos Inhumanos o Degradantes pueden consultarse electrónicamente en el siguiente enlace:
} 
tanto, inoperativos. Este hecho fue expresamente recogido en el Informe del Comité Europeo para la Prevención de la Tortura y de las Penas o Tratos Inhumanos o Degradantes, donde se constató la política expansionista en materia penitenciaria proyectándose la creación de 18.000 plazas más (9.000 celdas de uso compartido) para reducir la masificación de los centros, además de crear centros de régimen abierto como medio para ayudar a la reintegración de los reclusos en la sociedad, una situación no del todo acertada cuando el Comité solicitaba medidas más duraderas asociadas a una política vinculada con la promoción de sanciones vinculadas a alternativas a la pena de prisión $^{38}$.

Esta situación ha dado origen, como recoge la Defensora del Pueblo en su informe correspondiente al año 2015, a que, por ejemplo, el Centro Penitenciario de Archidona (Málaga) ${ }^{39}$ se encuentre cerrado, pese a ser de nueva construcción, situación que se repite en los de Soria y Ceuta, que el nuevo Centro Penitenciario de Valencia (Siete Aguas) esté paralizado, que la remodelación del Centro Penitenciario de Almería, ya concluida, esté pendiente de entrar en funcionamiento, al igual que ocurre con el de Teruel, o que el Centro Penitenciario de Guipúzcoa se encuentre en fase de remodelación sin que conste fecha de finalización de las obras. Respecto a los Centros de Inserción Social ocurre prácticamente lo mismo en tanto los de Almería o Ceuta están construidos pero cerrados a falta del equipamiento necesario mientras que los de Valencia y Las Palmas se encuentran en fase de obras ${ }^{40}$. A ellos hay que añadir la presencia de otros Centros Penitenciarios que se encuentran funcionando de manera parcial, como es el caso de Murcia II, en el que diversos módulos permanecen cerrados.

\footnotetext{
38 Informe al Gobierno Español sobre la visita a España realizada por el Comité Europeo para la Prevención de la Tortura y de las Penas o Tratos Inhumanos o Degradantes (CPT) llevada a cabo del 30 de mayo hasta el 13 de junio de 2011.

${ }^{39}$ Particularmente relevante es la situación de este Centro ya que, como ha denunciado ACAIP, cuenta con 1.008 celdas y lleva cerrado desde que se terminó en el año 2013 tras invertir 117 millones de euros, fecha desde la cual el Estado viene pagando a una empresa privada 3,27 millones de euros por tareas de mantenimiento y vigilancia. Véase, a tal el siguiente recurso electrónico:
}

https://www.acaip.es/es/noticias/medios-de-comunicacion/6035-interior-tiene-2700-celdas-sin-estrenarpor-falta-de-personal-pese-a-la-masificacion-de-las-carceles

40 DEFENSOR DEL PUEBLO, Informe Anual 2015 y debate en las Cortes Generales, Madrid, 2016, págs. 200 y 201. Recurso electrónico disponible en:

https://www.defensordelpueblo.es/wp-content/uploads/2016/02/Informe2015.pdf 
iii) Las tasas de población reclusa por cada 100.000 habitantes son especialmente preocupantes en el caso de España ya que reincide en el desgraciadamente ya clásico postulado de que se trata de uno de los países con menor criminalidad del entorno europeo pero por el que más fácilmente se ingresa en prisión, siendo el undécimo país europeo en presentar la tasa más alta (143,1 reclusos por cada 100.000 habitantes), teniendo por delante a países como Lituania, Letonia, Montenegro, Eslovaquia (...) quedando al nivel de Serbia $(144,6)$ o, lo que es más grave, duplicando la tasa de Alemania $(76,2)$, muy por encima de Italia $(88,2)$ o Inglaterra/Gales $(96,1)$, lo cual hace que España tenga el dudoso honor de ocupar los primeros puestos si la comparativa se reduce exclusivamente a los países miembros de la Unión Europea. Obviamente, las equiparaciones realizadas con los países enunciados no parece que sean las más adecuadas por el entorno socio-cultural, no haciendo más que reafirmar la pobre o nula repercusión que las alternativas a la prisión tienen en nuestro ordenamiento jurídico.

Semejante panorama tampoco es nuevo y ya fue advertido por Morillas Cueva al señalar que en España la situación estaba adquiriendo caracteres muy relevantes ya que mientras la criminalidad española está a niveles especialmente bajos dentro de la estructura punitiva europea, las cifras de personas encarceladas, como hemos visto, se muestra en los primeros lugares dentro del marco europeo, incluso en los últimos años donde se detecta un tenue descenso sin que ello oculte los importantes números ofrecidos, encontrándonos en parámetros muy alejados de una concepción reduccionista de la pena de prisión $^{41}$.

a2) Sanidad. Uno de los indicadores más observados y que a la vez suele demostrar la fortaleza de la institución penitenciaria radica en la sanidad. En España, se trata de una de las parcelas que funciona con mayor normalidad siendo un referente de ejemplaridad.

Ello, no obstante, no evita que existan disfunciones como en cualquier ámbito. En este sentido, la Defensora del Pueblo contabilizó un total de setenta y cuatro quejas de internos en relación a aspectos higiénico-sanitarios en su Informe de 2015, lo que

\footnotetext{
${ }^{41}$ MORILLAS CUEVA, L., "¿Pasa la legitimación..." cit., pág. 34.
} 
representa un $14 \%$ del total de las presentadas, si bien únicamente ha considerado dos asuntos como de especial relevancia: de un lado, la situación, personal y de medios de algunas enfermerías de los centros penitenciarios; y, por otro, el tratamiento que se dispensa a quienes se encuentran allí ingresados padeciendo una enfermedad mental ${ }^{42}$, situaciones que, por otro lado, no son nuevas y constituyen el principal caballo de batalla de la Administración penitenciaria en esta materia.

B) Victimización primaria propiamente dicha. Implicaría la comisión de hechos delictivos desarrollados dentro del Centro Penitenciario; esto es, la producción de delitos con la particularidad de que el sujeto pasivo es un agente interno del establecimiento penitenciario, independientemente del rol que ocupe (recluso, funcionario, personal externo, etc.), pero siempre y cuando se encuentre desarrollando su actividad en el seno de la institución.

$\mathrm{Su}$ contenido resulta muy heterodoxo en tanto engloba a cualquier tipología delictiva presente en el Código Penal capaz de poder ser desarrollada en el establecimiento penitenciario, debiendo excluirse, en consecuencia, las de realización imposible por las propias limitaciones de la prisión.

Las escasas manifestaciones doctrinales existentes apuntan casi siempre a un mismo ámbito y así, por ejemplo, Hikal ha referido expresamente las vinculadas a los internos victimizados por el maltrato del personal penitenciario ${ }^{43}$. En mi opinión, semejante categorización va a aquedar configurada por tres niveles: i) muertes en prisión, dado la evidente repercusión y afectación al principal bien jurídico protegido; ii) maltrato a los internos, como mecanismo tradicional aducido históricamente como práctica abusiva desarrollada en las prisiones; y iii) ilícitos comunes, donde se incluiría un cajón de sastre en el que se analizarán los restantes y principales hechos delictivos desarrollados, independientemente del sujeto pasivo, si bien aunque se vincula casi exclusivamente a los internos, nada impediría incluir también a los restantes miembros del Centro -por ejemplo, agresiones a funcionarios-.

\footnotetext{
${ }^{42}$ DEFENSOR DEL PUEBLO, Informe Anual 2015... cit., págs. 177 y 186-190.

${ }^{43}$ HIKAL, W., "El presente..." cit., pág. 4.
} 


\section{Doctrina y Jurisprudencia}

b1) Muertes en prisión. Como es sabido, la Administración ostenta una relación de especial sujeción respecto al interno en virtud de la cual, entre otras cuestiones, debe garantizar la vida de las personas privadas de libertad. En este sentido, López Melero considera que del mandato constitucional y del artículo 4 del Reglamento Penitenciario, el Estado tiene que cumplir con un doble deber: respetar las vidas y protegerlas, lo cual se traduce en el derecho de todo interno no sólo a la vida sino a que, dentro de lo posible, la Administración la proteja ${ }^{44}$.

La muerte en prisión ha sido siempre un tema tabú ante el que existía cierto miedo a reconocer la realidad de los centros en esta materia. Sin embargo, en los últimos años existe un mayor conocimiento y difusión, conociéndose datos estadísticos e incluso algunas publicaciones vinculadas a ámbitos muy particulares ${ }^{45}$.

En concreto, respecto a lo que ahora interesa, la Defensora del Pueblo ha compilado los datos referentes a las muertes acontecidas en los Centros Penitenciarios españoles, obteniendo algunos datos muy ilustrativos:

i) La tasa de fallecimientos dentro de las prisiones españolas presenta una línea claramente descendente durante la última década, tal y como puede corroborarse en el siguiente gráfico:

\footnotetext{
${ }^{44}$ LÓPEZ MELERO, M., Los derechos... cit., pág. 83.

${ }^{45}$ A modo de ejemplo, NEGREDO LÓPEZ, L.; MELIS PONT, F.; y HERRERO MEJÍAS, Ó. Factores de riesgo de la conducta suicida en internos con trastorno mental grave, Madrid, 2011.
} 


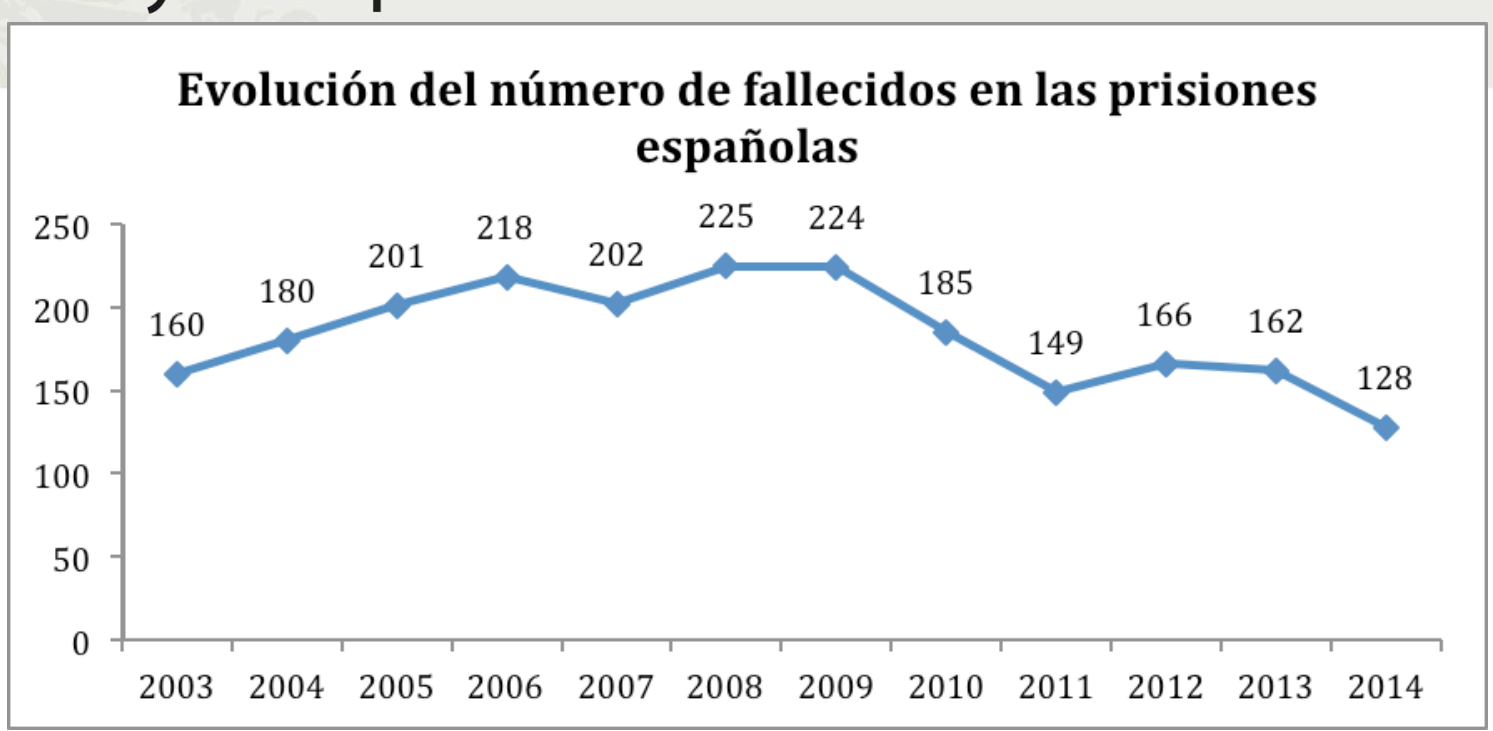

ii) La tasa de fallecidos por cada mil internos ha ido igualmente descendiendo hasta situarse en el nivel de los 2,25 por mil correspondientes al año 2014, lo que constituye la más baja de todas.

iii) En cuanto a caracteres personales, referir que, en el año 2014, el 93\% fueron varones y el 7\% mujeres; y que el 50\% de los fallecidos era menor de cuarenta y cinco años, si bien, por grupos de edad, el nivel más afectado fue el de los cuarenta y cinco a cincuenta años.

iv) Por último, en lo que ahora puede interesar más a la temática tratada, la causa de la muerte fue la siguiente:

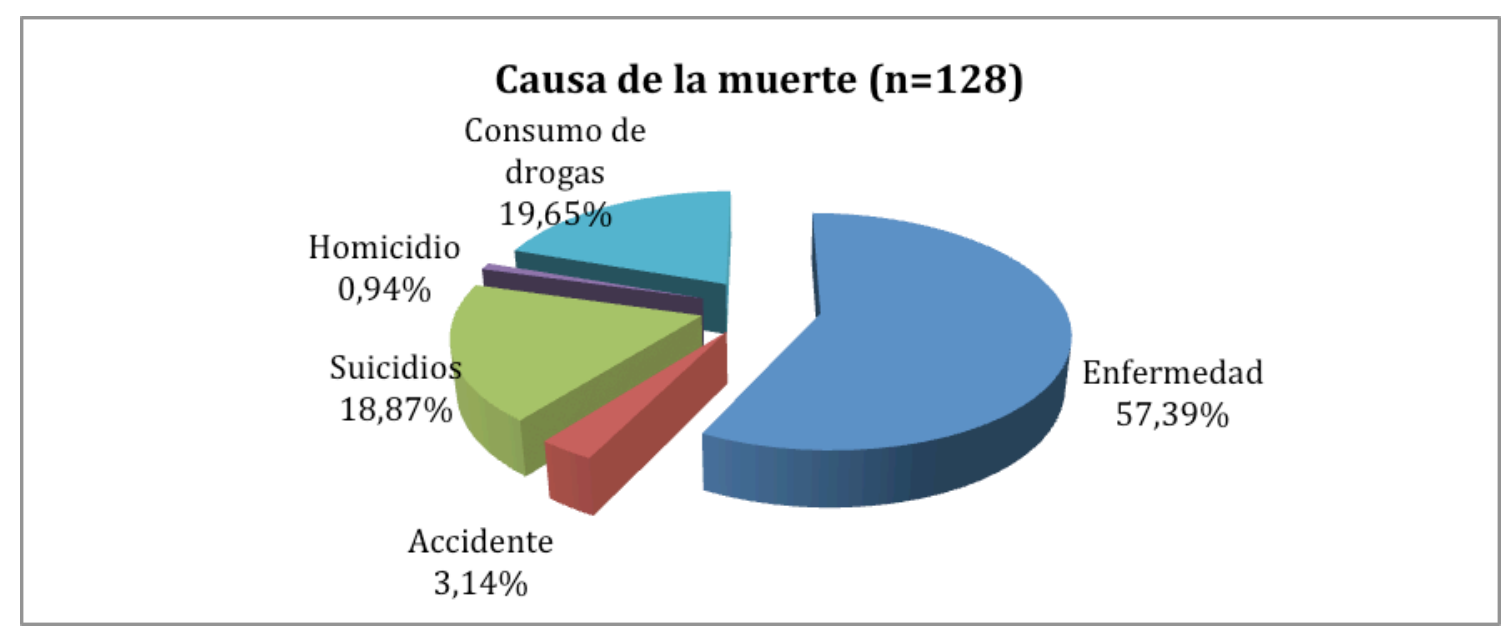


Como puede comprobarse, las muertes dolosas, ya sean como homicidio o asesinato, constituyen un porcentaje ínfimo respecto al total de muertes (2 sobre 128), manteniendo los parámetros habituales respecto a años anteriores ${ }^{46}$, en los que suelen oscilar entre uno y dos.

b2) Maltrato a internos. Como ya se ha referido, constituye el supuesto de victimización por antonomasia aducido históricamente e integraría la conducta por parte de los funcionarios de establecimientos penitenciarios a los internos consistente en actos que atenten contra su salud, integridad, dignidad (...). No se tiene inicialmente constancia de que semejantes prácticas se produzcan de manera habitual en los Centros Penitenciarios españoles, más bien lo contrario, se observan algunas situaciones esporádicas repartidas por el territorio español sin que exista una cuantificación particular al respecto más que la correspondiente denuncia del interno, conforme a los cauces legalmente establecidos, o las quejas interpuestas a la Defensora del Pueblo, la cual, en su Memoria de 2014 prestó una especial atención a este tipo de victimización, no en el sentido de su cómputo efectivo sino intentando articular un procedimiento con unas garantías probatorias que permitieran aclarar si realmente aconteció alguna práctica ilícita.

En este sentido, en la citada Memoria, puso de relieve diversas deficiencias de la Administración Penitenciaria para registrar las denuncias de los internos respecto a las actuaciones de los funcionarios de prisiones. Para ello, reclamó la implantación de un sistema de registro específico destinado a recoger las denuncias de internos a funcionarios por hechos graves, tales como maltrato, abusos sexuales u otras actividades irregulares. Por último, conviene destacar el especial énfasis puesto en el uso de los sistemas de videovigilancia como mecanismo probatorio o exculpatorio de las acusaciones realizadas, algo que opera en las prisiones más modernas pero carente en las más antiguas. No obstante, considera necesario articular una normativa específica en esta materia con la cual se obligue de oficio a la Administración para que conserve la grabación realizada en el momento en el que un interno interponga una denuncia o

\footnotetext{
${ }^{46}$ DEFENSOR DEL PUEBLO, Informe... cit., págs. 178-180.
} 


\section{Doctrina y Jurisprudencia}

queja, no procediendo al borrado de la misma transcurridos veinte días, tal y como acontece en la actualidad ${ }^{47}$.

Sin embargo, en la Memoria de 2015 se pone de manifiesto que las citadas actuaciones no han podido llevarse a cabo ya que la Administración Penitenciaria aduce que ya existe un cauce procedimental para la investigación y conocimiento de tales denuncias, pues desde los centros son remitidas a los servicios centrales, en concreto, a la unidad de inspección, donde se abren los correspondientes procedimientos de investigación. Frente a ello, la Defensora del Pueblo pretende fiscalizar semejante actuación a través de un ente externo al ámbito penitenciario para garantizar la objetividad del procedimiento ya que carece de sentido que sea uno de los responsables del centro quien efectúe las indagaciones pertinentes, debiendo ser un agente externo así como que se emita un informe valorativo del testimonio por profesionales especialistas de la conducta, miembros de la Administración, pero ajenos a la institución penitenciaria en la que se ha producido el hecho, manteniendo el resto de consideraciones $^{48}$.

b3) Ilícitos comunes entre internos. La presente hipótesis reviste una especial complejidad toda vez que la inmensa mayoría de casos quedan en el ámbito privado de la relación entre internos no siendo, para nada, habitual la denuncia. Se trata de un ámbito en el que hay un evidente oscurantismo para su determinación pero sobre lo que la Criminología y, particularmente, la Victimología cuenta con herramientas útiles para su detección. En este sentido, las encuestas de victimización y los autosondeos ${ }^{49}$ constituyen los mecanismos idóneos para computar los casos detectados y no declarados y los no detectados, conforme a lo expuesto en el epígrafe primero.

\footnotetext{
${ }^{47}$ DEFENSOR DEL PUEBLO, Informe anual 2014 y debates en las Cortes Generales, Madrid, 2015, págs. 153-157. Recurso electrónico disponible en:

https://www.defensordelpueblo.es/wp-content/uploads/2015/06/Informe2014.pdf

${ }^{48}$ DEFENSOR DEL PUEBLO, Informe... cit., págs. 182-186.

${ }^{49}$ Sobre el contenido de las encuestas de victimización, vid. MORILLAS FERNÁNDEZ, D. L.; PATRÓ HERNÁNDEZ, R. M.; Y AGUILAR CÁRCELES, M. M., Victimología... cit., págs. 139-142.
} 


\section{Doctrina y Jurisprudencia}

En España, una investigación de semejantes características fue llevada a cabo por Caravaca Sánchez, quien, en su tesis doctoral, procedió a cuantificar el fenómeno de la victimización en los Centros Penitenciarios de la Región de Murcia, para lo cual tomó una muestra de 661 internos, trabajo que igualmente a dado pie a otros importantes publicaciones en la materia ${ }^{50}$. Dada la relevancia y contenido de la investigación desarrollada, a continuación represento, a modo meramente ejemplificativo, algunas de las variables analizadas en la obra indicada, remitiéndome a las citadas publicaciones para una mayor profundización en la materia ${ }^{51}$ :

\section{¿Ha sufrido algún tipo de victimización? (n=661)}

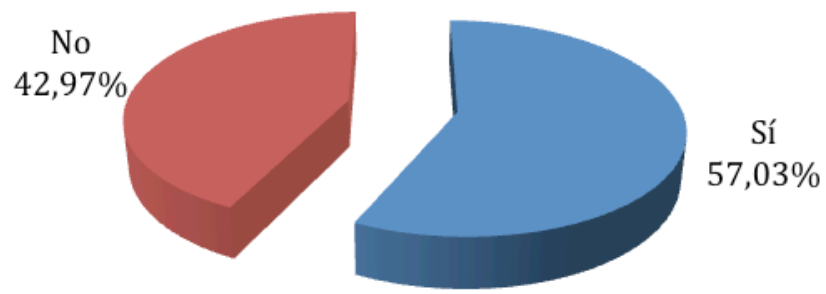

\footnotetext{
${ }^{50}$ Entre otras, CARAVACA SÁNCHEZ, F., SÁNCHEZ RODRÍGUEZ, F., LUNA MALDONADO, A., "Influence of sociodemographic and prison variables in processes of prison victmization", en Revista Española de Medicina Legal, 3-40, 2014, págs. 91-96; CARAVACA SÁNCHEZ, F., FALCÓN ROMERO, M., LUNA MALDONADO, A., "Agresiones físicas en prisión, la enfermedad mental como factor de riesgo asociado", en Revista Española de Sanidad Penitenciaria, $n^{\circ}$ 16, 2014, págs. 29-37; CARAVACA SÁNCHEZ, F. y WOLFF, N., "Prevalence and predictors of sexual victimization among incarcerated men and women in Spanish prisons", en Criminal justice and behavior, 43 (8), 2016, págs. 977-991.
}

${ }^{51}$ CARAVACA SÁNCHEZ, F., El fenómeno de la victimización en los Centros Penitenciarios de la Región de Murcia, Tesis doctoral, Murcia, 2013. 
Revista Internacional de

Doctrina y Jurisprudencia

Número de victimizaciones $(n=377)$

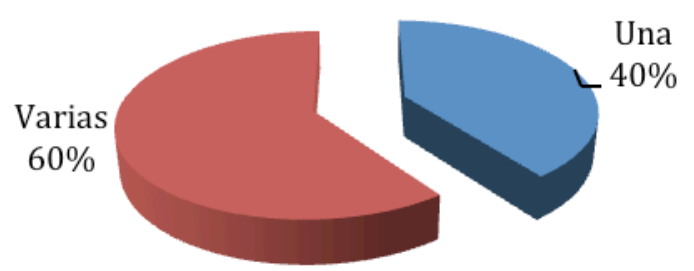

\begin{tabular}{|c|c|c|}
\hline $\begin{array}{c}\text { TIPO DE } \\
\text { VICTIMIZACIÓN }\end{array}$ & $\begin{array}{c}\text { NÚMERO DE } \\
\text { INTERNOS }\end{array}$ & $\begin{array}{c}\text { \% SOBRE LA POBLACIÓN } \\
\text { ENCUESTADA }\end{array}$ \\
\hline Insultos & 266 & $40,2 \%$ \\
\hline Hurtos & 206 & $31,2 \%$ \\
\hline Amenazas & 203 & $30,7 \%$ \\
\hline Asalto y/o atraco & 61 & $9,2 \%$ \\
\hline Lesión & 60 & $9 \%$ \\
\hline Agresión sexual & 43 & $6,5 \%$ \\
\hline
\end{tabular}

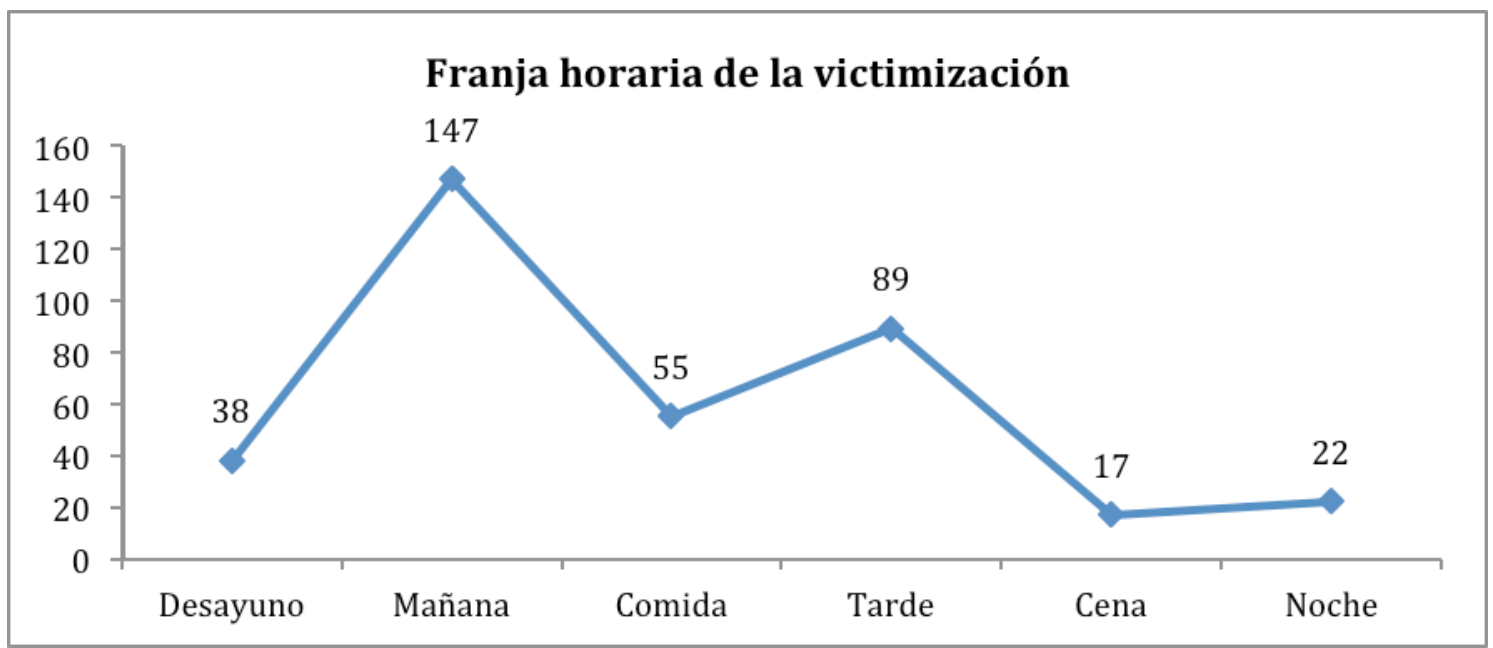




\section{Lugar de la victimización $(\mathrm{n}=377)$}

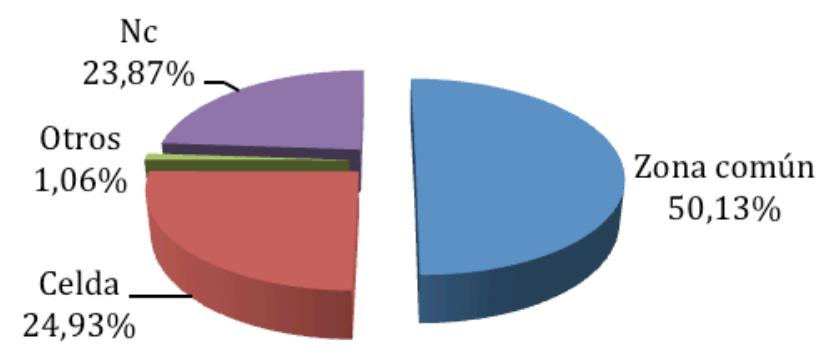

Un último dato muy clarificador radica en el grado de conocimiento de las victimizaciones penitenciarias. En este sentido, como señala Caravaca Sánchez en la investigación anteriormente descrita, un 70,9\% de los internos estudiados conocen al agresor en un caso de victimización penitenciaria, mientras un $69,9 \%$ hace lo propio con la víctima ${ }^{52}$, lo cual fortalece la idea de que la victimización penitenciaria es conocida por los propios internos pero respecto de la cual existe un secretismo a la hora de comunicarlo, constituyendo las encuestas de victimización o los autosondeos la herramienta más adecuada para contabilizarlos y conocer su fenomenología.

\section{CONCLUSIONES}

1. La victimización penitenciaria constituye una realidad que ha pasado desapercibida por los investigadores y la sociedad en general, no siendo capaz de traspasar los muros de la prisión. La ausencia de investigaciones, hasta fechas muy recientes, ha constituido la tónica general en la materia. No obstante, pese a tratarse de datos y actuaciones complejas de delimitar y cuantificar por las propias connotaciones subyacentes respecto a la población reclusa, la Victimología aporta los medios y herramientas necesarias para poder cuantificarla a través de las estadísticas victimales.

2. En la actualidad se han configurado tres niveles de victimización. La primaria, consistente en el proceso por el que una persona sufre, de modo directo o indirecto, los efectos nocivos derivados del delito o hecho traumático, independientemente de su

\footnotetext{
${ }^{52}$ Ibídem, pág. 406.
} 
naturaleza material o psíquica; la secundaria, la cual abarca los costes personales derivados de la intervención del sistema legal; y la terciaria, sobre la que no existe un consenso doctrinal respecto a su significación, pero que, en mi opinión, lejos de vincularla al delincuente, los testigos o los familiares de la pareja penal, debe circunscribirse a la reacción de la comunidad ante el cumplimiento de una sanción y la repercusión que semejantes hechos tienen en la víctima.

De acuerdo con lo anterior, la victimización penitenciaria representa un tipo de victimización primaria, independientemente de su origen, ya sea por una persona física o jurídica (Administración).

3. Respecto a las variables penitenciarias estudiadas, conviene destacar lo siguiente:

3.1. Se ha producido un descenso del $21,8 \%$ de la población reclusa española en los últimos siete años.

3.2. La absoluta primacía de la población reclusa masculina respecto a la femenina (92,5\% vs 7,4\%), perfil históricamente característico del sistema penitenciario español.

3.3. La especial representatividad de los internos entre veintiséis y cuarenta años en los Centros Penitenciarios españoles, destacando particularmente el segmento entre veintiséis y treinta años, donde se triplica la tasa que pudiera considerarse de representación normal.

3.4. El elevado número de internos extranjeros, prácticamente triplica la tasa media representativa de esta colectiva en la sociedad española, lo cual debe hacer reflexionar seriamente a los poderes públicos sobre los mecanismos de atención, recursos sociales y demás que afectan a la población extranjera, siendo necesaria una revisión y potenciación de los medios de control social informal en este sentido para vincularlos, aún más si cabe, hacia nuevas políticas de actuación e intervención de naturaleza social.

3.5. Seis de cada diez internos que cumplen condena en los establecimientos penitenciarios españoles lo hace por delitos contra el patrimonio y el orden socioeconómico o la salud pública. 
3.6. El $75 \%$ de los internos se encuentra cumpliendo condena en régimen ordinario.

4. La victimización penitenciaria, como modalidad de victimización primaria, incluiría a la persona que sufre, directa o indirectamente, los efectos nocivos derivados de un delito $o$ acto ilícito, independientemente de su naturaleza material o psíquica. En atención al sujeto causante, habría que distinguir dos tipologías: i) institucional, generada por la Administración Penitenciaria en el instante a partir del cual inobserve los derechos inherentes normativamente al interno; y ii) primaria propiamente dicha, la cual implicaría la comisión de hechos delictivos en el interior del Centro Penitenciario, con la particularidad de que el sujeto pasivo sería un agente interno del establecimiento, independientemente de su rol.

5. España es uno de los países europeos con menor nivel de masificación penitenciaria pero con mayor tasa de internos por cada 100.000 habitantes, lo cual supone una auténtica contradicción pero que tiene una explicación lógica en base a las siguientes premisas:

5.1. Tras los primeros Informes del Comité Europeo por la Prevención de la Tortura y de las Penas o Tratos Inhumanos o Degradantes, donde se alertaba que la masificación de los Centros Penitenciarios españoles llegó a situarse en el 143\%, se inició una política de construcción de centros penitenciarios con el propósito de disminuir el citado porcentaje. Sin embargo, la reducción de la población reclusa en un $21 \%$ ha hecho que muchas de las plazas penitenciarias de nueva creación estén inutilizadas por no ser necesarias, lo que ha originado que existan en la actualidad Centros Penitenciarios completamente cerrados y otros abiertos de manera parcial en tanto cuentan con módulos inoperativos y, en consecuencia, vacíos.

Este hecho evidencia un desembolso económico innecesario, una falta de proyección, miras y alternativas preocupante y una descoordinación de la propia Administración ya que, por un lado, se aceleran las excarcelaciones de internos a través de la aplicación expansiva de la libertad condicional y, por otro, se crean más centros penitenciarios que, conforme a esa política, carece de sentido si no es para sustituir a otros más antiguos, situación que hasta la fecha, no se ha producido. El resultado de la citada estrategia es más alarmante: Centros cerrados, obras paralizadas y desembolsos económicos importantes en mantenimiento y vigilancia de prisiones vacías, lo cual se agrava aún más cuando de lo que se trataba era de 


\section{Doctrina y Jurisprudencia}

potenciar las alternativas a la pena de prisión, tal y como se reclamó desde el Consejo de Europa.

5.2. La elevada tasa de población reclusa por 100.000 habitantes no es más que la corroboración empírica de un mal endémico del sistema español: la enorme facilidad con la que los ciudadanos ingresan en prisión; esto es, España es uno de los países con menor criminalidad en Europa -y en la Unión Europea- pero con mayores tasas de prisionización por habitante, lo cual tiene una clara explicación: la ausencia o ineficacia de las alternativas a la pena de prisión.

6. La victimización penitenciaria primaria propiamente dicha no presenta tasas ni datos que excedan de lo que podría considerarse como normal conforme a las particularidades del ámbito penitenciario. No obstante, sí conviene advertir la necesidad de mejora requerida en el procedimiento de denuncia en los casos de maltrato a internos, a lo que la Defensora del Pueblo pretende instaurar una serie de mejoras que considero esenciales $y$, sobre todo, garantistas, las cuales se basan en la imparcialidad del procedimiento y la utilización adecuada y continua de medios tecnológicos como elementos probatorios, eliminando, con ello, prácticas indeseadas.

Finalmente, respecto a la violencia entre internos, la investigación reseñada de Caravaca Sánchez, ha puesto de manifiesto que las principales formas de victimización son de niveles lesivos menores, primando los insultos, hurtos y amenazas; reduciéndose las de naturaleza violenta por debajo del $10 \%$-asaltos, lesiones y agresiones sexuales-. 